Article

\title{
Evaluation of Different Radiative Transfer Models for Microwave Backscatter Estimation of Wheat Fields
}

\author{
Thomas Weiß *(D), Thomas Ramsauer (D), Alexander Löw (D) and Philip Marzahn (i) \\ Department of Geography, Ludwig-Maximilians-Universität München, Luisenstraße 37, \\ 80333 Munich, Germany; t.ramsauer@iggf.geo.uni-muenchen.de (T.R.); alexander.loew@lmu.de (A.L.); \\ p.marzahn@iggf.geo.uni-muenchen.de (P.M.) \\ * Correspondence: weiss.thomas@lmu.de
}

Received: 28 July 2020; Accepted: 10 September 2020; Published: 17 September 2020

\begin{abstract}
This study aimed to analyze existing microwave surface (Oh, Dubois, Water Cloud Model "WCM", Integral Equation Model "IEM") and canopy (Water Cloud Model "WCM", Single Scattering Radiative Transfer "SSRT") Radiative Transfer (RT) models and assess advantages and disadvantages of different model combinations in terms of VV polarized radar backscatter simulation of wheat fields. The models are driven with field measurements acquired in 2017 at a test site near Munich, Germany. As vegetation descriptor for the canopy models Leaf Area Index (LAI) was used. The effect of empirical model parameters is evaluated in two different ways: (a) empirical model parameters are set as static throughout the whole time series of one growing season and (b) empirical model parameters describing the backscatter attenuation by the canopy are treated as non-static in time. The model results are compared to a dense Sentinel-1 C-band time series with observations every 1.5 days. The utilized Sentinel-1 time series comprises images acquired with different satellite acquisition geometries (different incidence and azimuth angles), which allows us to evaluate the model performance for different acquisition geometries. Results show that total LAI as vegetation descriptor in combination with static empirical parameters fit Sentinel-1 radar backscatter of wheat fields only sufficient within the first half of the vegetation period. With the saturation of LAI and/or canopy height of the wheat fields, the observed increase in Sentinel-1 radar backscatter cannot be modeled. Probable cause are effects of changes within the grains (both structure and water content per leaf area) and their influence on the backscatter. However, model results with LAI and non-static empirical parameters fit the Sentinel-1 data well for the entire vegetation period. Limitations regarding different satellite acquisition geometries become apparent for the second half of the vegetation period. The observed overall increase in backscatter can be modeled, but a trend mismatch between modeled and observed backscatter values of adjacent time points with different acquisition geometries is observed.
\end{abstract}

Keywords: Oh; Dubois; IEM; WCM; SSRT; SAR; soil moisture; LAI; wheat; Sentinel-1

\section{Introduction}

Soil moisture plays an important role in land surface processes, such as water and energy fluxes. Therefore, soil moisture is a key variable in scientific fields like climatology, hydrology, meteorology, or agriculture [1,2]. In recent decades, microwave data has proven to be a suitable tool for long-term soil moisture derivation of large areas and different land cover types [3-9]. The retrieved soil moisture information is widely used in applications, like climate modeling, precision farming, water management, flood forecast, and drought monitoring [10-14]. With different available Synthetic Aperture Radar (SAR) data from different sensors and for different usage in terms of absolute accuracy and spatial scale, various soil moisture retrieval approaches, like change detection, microwave data fusion (active and passive), differential Synthetic Aperture Radar (SAR) interferometry, or 
SAR polarimetry, are available [15]. Furthermore, land surface parameters, like soil moisture, can be also derived by using Radiative Transfer (RT) models. Starting in 1974 [16], with the first publication examining radar response and soil moisture [17], hundreds of different studies developing and/or analyzing new or existing RT models have been conducted. RT models try to simulate the interaction of the radar wave with the soil and the vegetation to derive different soil and vegetation parameters [18]. Complexities in RT models for surface backscatter calculations range from simple empirical regression-based models [18-21] and different empirical models based on the Water Cloud approach (WCM surface part) [22-25], over semi-empirical models from Oh (Oh92, Oh04) [26,27] or Dubois (Dubois95), [28] to physical-based models, like the Integral Equation Model (IEM) in its original form [29] or refined versions [30-32]. Common RT models for canopy backscatter calculations range from empirical models, like Water Cloud Model (WCM canopy part) [22], to more sophisticated and multi-layered models, like the Michigan Canopy Scattering Model (MIMICS) [33], Tor Vergata model [34], Single Scattering Radiative Transfer (SSRT) models described by De Roo [35] or Ulaby [17], or a first order scattering model from Quast [36,37]. Despite the large numbers of existing models, there is still the need of an algorithm generating soil moisture maps with acceptable accuracy of 3-4\% [17].

So far, several studies have been carried out to test and compare pure surface RT models [15,38-42]. Research analyzing radar backscatter calculations and soil moisture retrieval approaches of combined surface and canopy RT models has been performed. For these studies different test sites, land cover types, and vegetation descriptors were used [25,43-55]. Investigations on how different vegetation descriptors, like Leaf Area Index (LAI), Vegetation Water Content (VWC), Leaf Water Area Index (LWAI), normalized Plant Water Index (PWI), or Normalized Different Water Index (NDWI), affect soil moisture retrievals have been carried out, as well [25,48,53,54]. In this context, synergistic retrieval approaches by using vegetation descriptors derived from optical sensors as input data for microwave RT models have been published more and more in recent years [45,52,56-61].

Despite the existing analyses, a study testing and comparing different surface and canopy RT model combinations with focus on the interaction between surface and canopy part and advantages or disadvantages of the model combinations is missing. The launch of Sentinel-1A/B, and, therefore, the availability of free SAR data with high temporal and spatial coverage, constitutes a suitable basis for such an analysis. Investigations of the usage of dense Sentinel-1 time series with observations up to every 1.5 days in terms of future synergistic retrieval approaches of SAR and optical data are needed. The models and the knowledge gained from this paper shall be used within a newly developed platform called MULTIPLY, which combines data from different optical and microwave satellites by using state-of-the-art RT models within a data assimilation framework to consistently acquire and interpret different land surface parameters.

This study was performed on time series data with high temporal and spatial (field scale) resolution. The surface RT models WCM, Oh92, Oh04, Dubois95, and IEM were coupled with canopy models WCM or SSRT. With these model combinations, VV polarized backscatter values for an entire vegetation period of different wheat fields was calculated. The different input variables for the model combinations, such as soil moisture, canopy height, LAI, or soil properties, were provided by field measurements. For other parameters, like surface roughness or single scattering albedo, suitable literature values were chosen. LAI was used as vegetation descriptor because of available field measurements and its straight forward derivation from optical sensors [62-64]. The remaining empirical parameters were calibrated by comparing modeled backscatter with Sentinel-1 backscatter values. In summary, this paper aimed to

- investigate different RT model combinations and asses their advantages and disadvantages;

- evaluate if different radar acquisition geometries are modeled adequately with the used RT models; and

- $\quad$ serve as preliminary work for future synergistic retrieval approaches of SAR and optical sensors with a focus on high spatial and temporal resolutions. 
Section 2 presents the used dataset. Section 3 summarizes the used RT models. In Section 4, calibration and validation results are shown and discussed. Finally, the main conclusions are drawn in Section 5.

\section{Datasets}

\subsection{Study Area}

The study area, Munich North Isar (MNI), is located in southern Germany (Bavaria), near Munich $\left(48^{\circ} 13^{\prime} \mathrm{N}-48^{\circ} 20^{\prime} \mathrm{N}, 11^{\circ} 39^{\prime} \mathrm{E}-11^{\circ} 45^{\prime} \mathrm{E}\right.$, Figure 1). Since 2014 , almost every year from spring until autumn, different field campaigns targeting agricultural purposes were carried out [65-68]. From March to September 2017, an intensive field campaign focusing on maize and wheat fields for validation of soil and vegetation parameter retrievals from Sentinel-1, Sentinel-2 and the future EnMAP satellite was conducted. MNI is characterized by intensive agriculture with wheat, maize, and grassland as main crop types. In close vicinity $(<10 \mathrm{~km})$ to the test site two meteorological stations, Freising ( $470 \mathrm{~m}$ a.s.1.) and Eichenried ( $475 \mathrm{~m}$ a.s.1.) managed by the Bavarian State Research Institute (LFL) and one meteorological station Munich-airport (446 m a.s.l.) managed by the German Meteorological Service (DWD) are situated. The annual measured mean temperature for 2017 ranges between $9{ }^{\circ} \mathrm{C}$ (Freising) and $9.3^{\circ} \mathrm{C}$ (Eichenried). The average annual precipitation for 2017 reached $753 \mathrm{~mm}$ (Munich-airport) to $853 \mathrm{~mm}$ (Eichenried). The used data for this study includes field campaign data of wheat fields from 2017 (Section 2.2) and Sentinel-1 satellite data (Section 2.3).

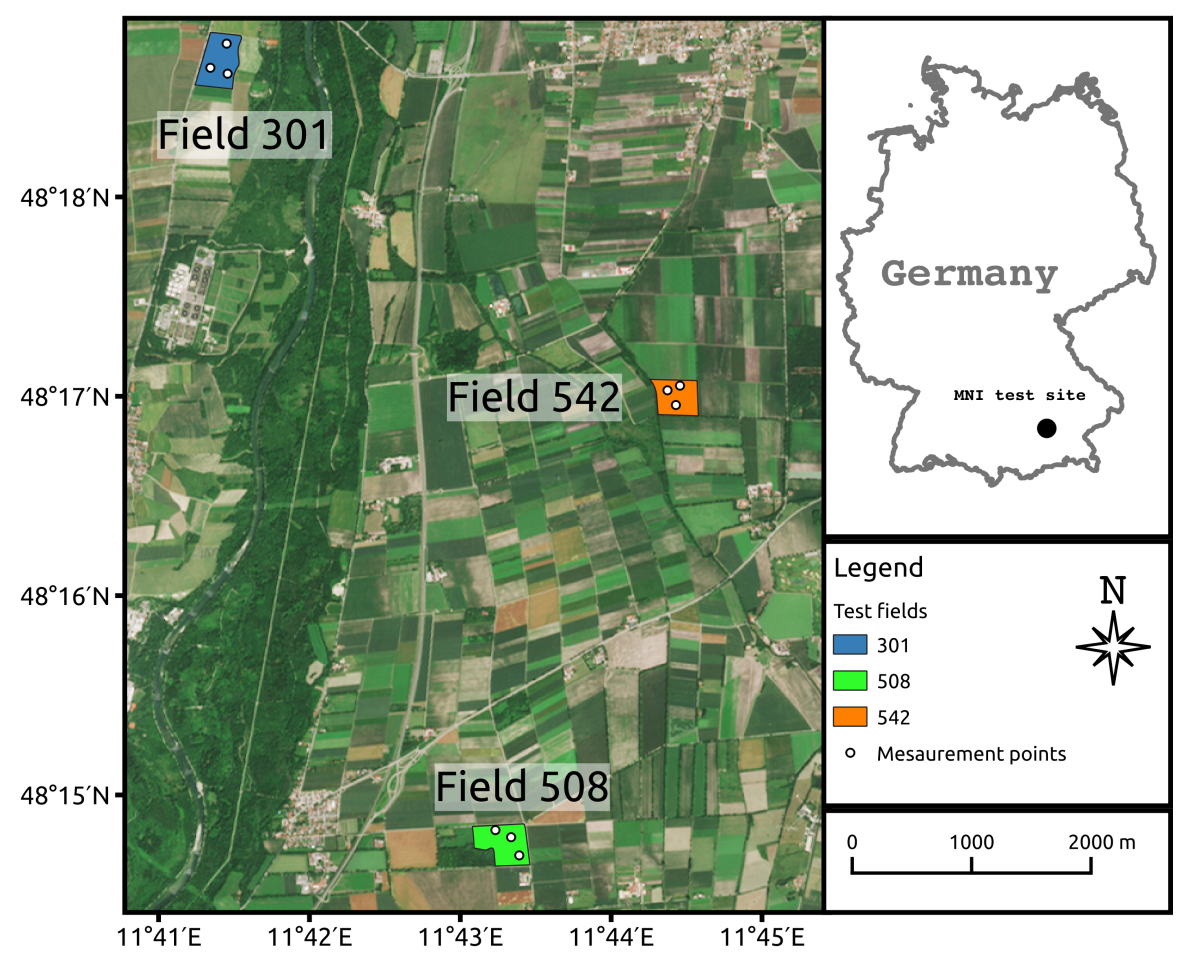

Figure 1. Overview of study area Munich-North-Isar (MNI) located in southern Germany (Bavaria). Three wheat test fields—508 (green), 542 (orange), and 301 (blue)—with three measurement points each of the field campaign in 2017 are highlighted. Reference system: WGS84 (EPSG:4326)

\subsection{Field Data}

During the MNI field campaign of 2017, weekly field measurements of different biophysical parameters (Table 1) were conducted. The total LAI was measured with a LI-COR Biosciences LAI-2200C device (LI-COR Biosciences Inc., Lincoln, NE, USA) as an average of 14 measurements 
from the same area. The measurements were taken within each test field at three different locations (Figure 1). The accuracy of LAI in terms of mean standard deviation of repeated measurements ranges within the fields between 0.45 and 0.52 . The monitoring period started end of March and ended shortly before the fields were almost simultaneously harvested in mid of July. Additionally, Decagon TM5 soil moisture sensors using the capacity method were installed permanently within the first five centimeters of the soil surface. Soil moisture changes were monitored with a time interval of $10 \mathrm{~min}$. Information about the soil was provided by earlier campaigns when soil samples were taken from the fields, and the soil properties were analyzed in the laboratory (Table 2). The soils bulk density with $1.45 \pm 0.13 \mathrm{~g} / \mathrm{cm}^{3}$, and the clay content with $7.38 \pm 1.8 \%$, show no high variability between the different fields. The sand content, on the other hand, shows higher variability, with $24.08 \pm 10.46 \%$.

Table 1. Acquisition time, time interval, and range of dynamic in-situ measurements.

\begin{tabular}{cccc}
\hline Variable & Acquisition Time & Time Interval & Range \\
\hline Canopy height $[\mathrm{cm}]$ & $03 / 24-07 / 17 / 2017$ & weekly & $7-105$ \\
LAI & $03 / 24-07 / 17 / 2017$ & weekly & $0.35-6.25$ \\
Soil moisture $\left[\mathrm{m}^{3} / \mathrm{m}^{3}\right]$ & $03 / 24-07 / 17 / 2017$ & continues & $0.09-0.38$ \\
\hline
\end{tabular}

Table 2. Laboratory results for sand, clay, and bulk content of soil surface samples.

\begin{tabular}{cccc}
\hline Variable & Time Interval & Mean & Std \\
\hline Soil sand content $[\%]$ & once (several locations) & 24.08 & 10.46 \\
Soil clay content $[\%]$ & once (several locations) & 7.38 & 1.80 \\
Bulk density $\left[\mathrm{g} / \mathrm{cm}^{3}\right]$ & once (several locations) & 1.45 & 0.13 \\
\hline
\end{tabular}

\subsection{Satellite Data}

For this study, C-band Sentinel-1 SLC data of Sentinel-1A/B was used. The Sentinel data was pre-processed with ESA's SNAP Toolbox Version 7.0.3. An overview of all applied pre-processing steps is given in Figure 2. For the geometric correction, SRTM data with 1 arc-second resolution was chosen as digital elevation model input. Afterward, the radiometric correction method of Kellndorfer et al. [69] was applied. In a second pre-processing step, a multi-temporal Lee-sigma filter was used for speckle reduction. The temporal filter was applied on each image with information of 6 other images (three before the target and three after) with a spatial window size of $5 \times 5$ pixels, a sigma of 0.9 , and a target window size of $3 \times 3$ pixels. For the period of the field campaign in 2017 (March to July), in total, 78 Sentinel images covering the study area are available. Considering images with different orbit directions (ascending and descending) and different incidence angles (ranges from $35^{\circ}$ to $45^{\circ}$ ) a revisit time of 1.5 days was archived. The spatial resolution of the processed data was $10 \times 10 \mathrm{~m}$. A more detailed overview of the used Sentinel-1 dataset and the image properties is given in Table 3. The primary acquisition mode of Sentinel-1 provides data with polarization VV and VH. For our study, the focus was set on polarization VV due to findings that, for retrieving soil moisture, the usage of $\mathrm{VH}$ alone or in addition to $\mathrm{VV}$ is not suitable for well-developed vegetation $[45,70]$.

Table 3. Available Sentinel-1A/B satellite data for MNI field campaign period in 2017 (03/23-07/17/2017).

\begin{tabular}{cccccc}
\hline Asc./Desc. & Incidence Angle $\left[{ }^{\circ}\right]$ & Relative Orbit & Amount & Revisit Time [Days] & Acquisition Time \\
\hline \multirow{2}{*}{ Ascending } & 36 & 44 & 19 & 6 & $4: 58$ p.m. \\
& 45 & 117 & 19 & 6 & 5:06 p.m. \\
\hline \multirow{2}{*}{ Descending } & 43 & 95 & 20 & 6 & $5: 17$ a.m. \\
& 35 & 168 & 20 & 6 & 5:25 a.m. \\
\hline
\end{tabular}




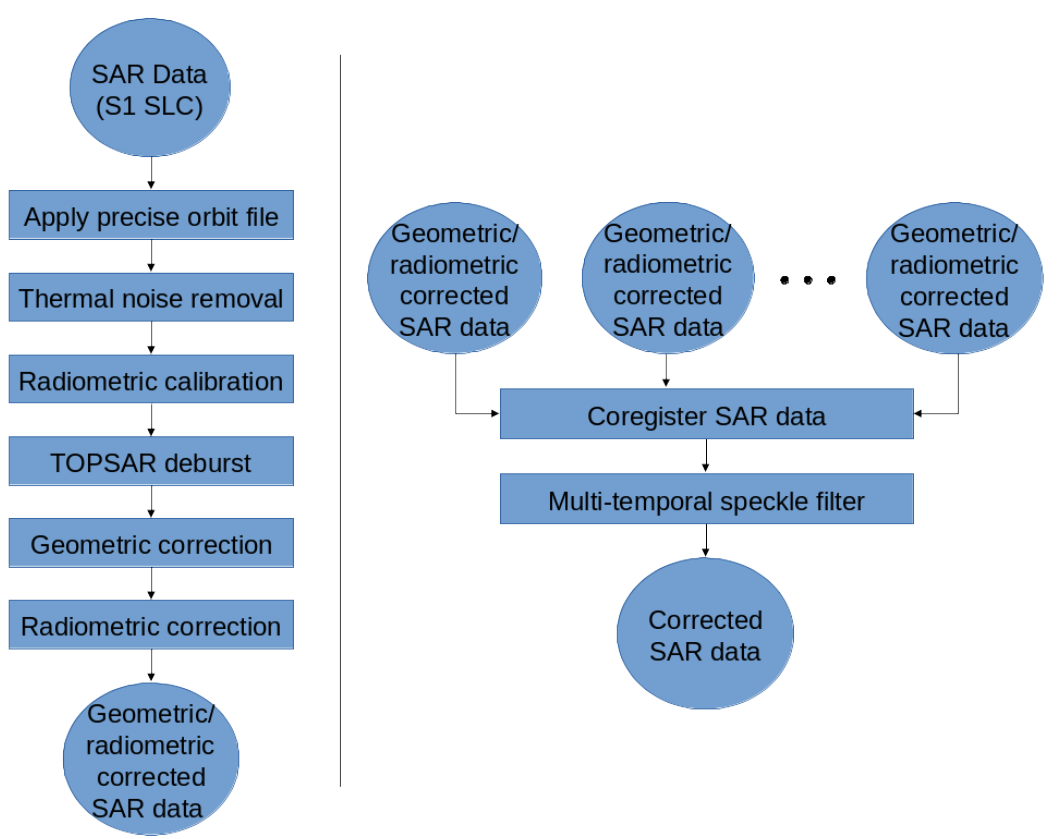

Figure 2. Schematic overview of SNAP pre-processing steps to retrieve geometric and radiometric corrected images from Sentinel-1 SLC data (left). Pre-processing steps for speckle reduction using a multi-temporal speckle filter (right).

\section{Microwave Radiative Transfer Models}

\subsection{Surface RT Models}

\subsubsection{Empirical Water Cloud Model (WCM Surface Part)}

The WCM, often referred to as the tau-omega model, was developed by Attema and Ulaby in 1978 [22]. For a given polarization $p q(p q=H H, V V$, or $H V)$, the surface contribution $\sigma_{s p q}^{0}$ of WCM to the backscattered radar signal in $\mathrm{dB}$ scale is defined as

$$
\sigma_{s_{p q}}^{0}=C_{p q}+D_{p q} \cdot m v
$$

with empirical fitted soil parameters $C_{p q}$ and $D_{p q}$ and soil moisture content $m v . C_{p q}$ is an empirical calibration constant, whereas $D_{p q}$, as a calibration factor, indicates the sensitivity of soil moisture on the received radar signal. The WCM surface part is a purely empirical model thus no additional information about surface roughness or incidence angle is needed. Therefore, the empirical parameters have to be calibrated for each test site separately.

\subsubsection{Semi-Empirical Oh Model 1992 (Oh92)}

In 1992, Oh et al. [26] developed an approach for the retrieval of soil moisture and soil surface roughness by empirical determined functions. Based on scatterometer measurements and various ground measurements of soil moisture and surface roughness, two functions for the co- $\left(p=\frac{\sigma_{s_{H H}}^{0}}{\sigma_{s_{V V}}^{0}}\right)$ and cross-polarized $\left(q=\frac{\sigma_{s_{H V}}^{0}}{\sigma_{s_{V V}}^{0}}\right)$ backscatter ratios were fitted. Consequently, $p$ and $q$ are defined as

$$
p=\frac{\sigma_{s_{H H}}^{0}}{\sigma_{s_{V V}}^{0}}=\left[1-\left(\frac{2 \theta}{\pi}\right)^{\frac{1}{3 R_{0}}} \cdot e^{-k s}\right]^{2}
$$


and

$$
q=\frac{\sigma_{s_{H V}}^{0}}{\sigma_{s_{V V}}^{0}}=0.23 \sqrt{R_{0}}\left(1-e^{-k s}\right),
$$

with $\theta$ as local incidence angle, $k$ as radar wave number $(k=2 \pi / \lambda)$, where $\lambda$ is the wavelength, and $s$ as rms height. $R_{0}$ is the Fresnel reflectivity coefficient at nadir given by

$$
R_{0}=\left|\frac{1-\sqrt{\epsilon_{r}}}{1+\sqrt{\epsilon_{r}}}\right|^{2}
$$

where $\epsilon_{r}$ is the relative dielectric constant. The $V V$ polarized backscatter coefficient $\sigma_{s_{V V}}^{0}$ is further defined as

$$
\sigma_{s_{V V}}^{0}=0.7\left[1-e^{-0,65(k s)^{1.8}}\right] \frac{\cos ^{3} \theta}{\sqrt{p}}\left[R_{v}(\theta)+R_{h}(\theta)\right],
$$

with the Fresnel coefficients for horizontal $R_{h}$ and vertical $R_{v}$ polarization

$$
\begin{aligned}
& R_{h}=\frac{\mu_{r} \cos \theta-\sqrt{\mu_{r} \epsilon_{r}-\sin ^{2} \theta}}{\mu_{r} \cos \theta+\sqrt{\mu_{r} \epsilon_{r}-\sin ^{2} \theta}}, \\
& R_{v}=\frac{\epsilon_{r} \cos \theta-\sqrt{\mu_{r} \epsilon_{r}-\sin ^{2} \theta}}{\epsilon_{r} \cos \theta+\sqrt{\mu_{r} \epsilon_{r}-\sin ^{2} \theta}},
\end{aligned}
$$

where $\mu_{r}$ is the relative permittivity. Furthermore, the backscatter coefficients $\sigma_{s_{H H}}^{0}$ and $\sigma_{s_{H V}}^{0}$ are given with respect to $\sigma_{s_{V V}}^{0}, p$, and $q$ by

$$
\begin{aligned}
& \sigma_{s_{H H}}^{0}=p \sigma_{s_{V V}}^{0}, \\
& \sigma_{s_{H V}}^{0}=q \sigma_{s_{V V}}^{0} .
\end{aligned}
$$

The model in its original form can be applied for the retrieval of soil moisture or soil surface roughness for bare soil conditions at several frequencies ( $X$ - to L-Band) and a broad range of incidence angles $\left(10-70^{\circ}\right)$. Because it is a semi-empirical model, the validity range of the model in terms of soil moisture and soil surface roughness is defined with $0.1<k s<6$, and 9 Vol. $\%<m v<31$ Vol.\%.

\subsubsection{Semi-Empirical Oh Model 2004 (Oh04)}

In 2004, Oh [27] revised and simplified his original approach to use only soil moisture ( $m v)$ as an independent variable rather than $R_{0}$ and $\epsilon_{r}$ (Section 3.1.2). Thus, if using $m v$ as input variable, no additional information about the soil properties (bulk density, sand and clay content) is needed. The model is defined by

$$
\begin{gathered}
p=\frac{\sigma_{s_{H H}}^{0}}{\sigma_{s_{V V}}^{0}}=1-\left(\frac{2 \theta}{\pi}\right)^{0.35 m v^{-0.63}} \cdot e^{-0.4(k s)^{1.4}}, \\
q=\frac{\sigma_{s_{H V}}^{0}}{\sigma_{s_{V V}}^{0}}=0.095\left(0.13+\sin ^{1.5} \theta\right)^{1.4}\left[1-e^{-1.3(k s)^{0.9}}\right], \\
\sigma_{s_{H V}}^{0}=0.11 m v^{0.7}(\cos \theta)^{2.2}\left[1-e^{-0.32(k s)^{1.8}}\right] .
\end{gathered}
$$

Oh04 is optimized for bare soils with $0.13<k s<6.98,4$ Vol. $\%<m v<29.1$ Vol.\% and $10^{\circ}<\theta<70^{\circ}$.

\subsubsection{Semi-Empirical Dubois Model (Dubois95)}

Dubois et al. [28] proposed, in 1995, an empirical approach to determine backscatter values for $\mathrm{HH}$ and $V V$ polarizations based on soil moisture, soil surface roughness, and system parameters, like local 
incidence angle, wavelength, and frequency. Two non-linear equations were fitted to measured backscatter values obtained by a scatterometer for a broad range of frequencies ranging from $2.5 \mathrm{GHz}$ to $11 \mathrm{GHz}$ and incidence angles ranging from $30^{\circ}$ to $60^{\circ}$. The backscatter values can be calculated by

$$
\begin{aligned}
& \sigma_{s_{H H}}^{0}=10^{-2.75} \frac{\cos ^{1.5} \theta}{\sin ^{5} \theta} 10^{0.028 \epsilon_{r} \tan \theta}(k s \cdot \sin \theta)^{1.4} \lambda^{0.7}, \\
& \sigma_{s_{V V}}^{0}=10^{-2.37} \frac{\cos ^{3} \theta}{\sin ^{3} \theta} 10^{0.046 \epsilon_{r} \tan \theta}(k s \cdot \sin \theta)^{1.1} \lambda^{0.7} .
\end{aligned}
$$

The Dubois model was optimized for bare soil conditions and has a validity range for soil moisture of $m v \leq 35 \mathrm{Vol} . \%$ and soil surface roughness of $k s \leq 2.5$.

\subsubsection{Physical Integral Equation Model (IEM)}

The IEM is a theoretical backscattering model and was developed by Fung et al. [29] in 1992. Since then, Fung and colleagues extended the IEM to bistatic scattering [71]. The general co-polarized backscatter coefficient $\sigma_{p p}^{0}$ for $p p=V V$ or $H H$ is defined as

$$
\sigma_{s p p}^{0}=\frac{k^{2}}{4 \pi} e^{k^{2} s^{2} \cos ^{2} \theta} \sum_{n=1}^{\infty}\left|I_{p p}^{n}\right|^{2} \frac{W^{n}(2 k \sin \theta, 0)}{n !},
$$

where $I_{p p}^{n}$ is

$$
I_{p p}^{n}=(2 k s \cos \theta)^{n} f_{p p} e^{-k^{2} s^{2} \cos ^{2} \theta}+(k s \cos \theta)^{n} F_{p p},
$$

with $W^{n}$ as the Fourier transform of the nth power of the surface correlation function $p(x, y)$. Furthermore, the backscatter at cross polarization $\sigma_{s_{H V}}^{0}$ is calculated as

$$
\begin{aligned}
\sigma_{s_{H V}}^{0} & =\frac{k^{2}}{16 \pi} e^{-2 k^{2} s^{2} \cos ^{2} \theta} \sum_{n=1}^{\infty} \sum_{m=1}^{\infty} \frac{\left(k^{2} s^{2} \cos ^{2} \theta\right)^{n+m}}{n ! m !} \\
& \int\left[\left|F_{H V}(u, v)\right|^{2}+F_{H V}(u, v) F_{H V}^{*}(-u,-v)\right] W^{n}(u-k \sin \theta, v) W^{m}(u+k \sin \theta) d u d v .
\end{aligned}
$$

The Kirchhoff coefficients $f_{H H}, f_{V V}$ and complementary field coefficients $F_{H H}, F_{V V}, F_{H V}$ are given as

$$
\begin{aligned}
f_{H H} & =\frac{2 R_{h}}{\cos \theta}, \\
f_{V V} & =\frac{2 R_{v}}{\cos \theta}, \\
F_{H H} & =2 \frac{\sin ^{2} \theta}{\cos \theta}\left[4 R_{h}-\left(1-\frac{1}{\epsilon_{r}}\left(1+R_{h}\right)^{2}\right)\right], \\
F_{V V} & =2 \frac{\sin ^{2} \theta}{\cos \theta}\left[\left(1-\frac{\epsilon \cos ^{2} \theta}{\mu_{r} \epsilon_{r}-\sin ^{2} \theta}\right)\left(1-R_{v}\right)^{2}+\left(1-\frac{1}{\epsilon_{r}}\right)\left(1+R_{v}\right)^{2}\right], \\
F_{H V}(u, c) & =\frac{U v}{k \cos \theta}\left[\frac{8 R^{2}}{\sqrt{k^{2}-u^{2}-v^{2}}}+\frac{-2+6 R^{2}+\frac{(1+R)^{2}}{\epsilon_{r}}+\epsilon_{r}(1-R)^{2}}{\sqrt{\epsilon_{r} k^{2}-u^{2}-v^{2}}}\right],
\end{aligned}
$$

with Fresnel coefficient at horizontal $R_{h}$ (Equation (6)) and vertical $R_{v}$ (Equation (7)) polarization thus $R$ is described by

$$
R=\frac{R_{v}-R_{h}}{2}
$$

The Fourier transform of the nth power of the surface correlation coefficient $W^{n}(a, b)$ is calculated by

$$
W^{n}(a, b)=\frac{1}{2 \pi} \iint p^{n}(x, y) e^{-i(a x+b y)} d x d y
$$


The distribution of surface correlation function $p(x, y)$ can be described for low surface roughness as exponential and high surface roughness values as Gaussian by

$$
\begin{aligned}
& p(x, y)=e^{-\left(\frac{|x|+|y|}{L}\right)}(\text { exponential }), \\
& p(x, y)=e^{-\left(\frac{x^{2}+y^{2}}{L^{2}}\right)}(\text { Gaussian }),
\end{aligned}
$$

with $L$ as correlation length.

\subsection{Surface and Canopy RT Models}

\subsubsection{Empirical Water Cloud Model (WCM)}

The WCM [22] with respect to surface $\sigma_{s_{p q}}^{0}$ and canopy $\sigma_{c_{p q}}^{0}$ contribution, as well as two-way attenuation $T_{p q}^{2}$, is defined as

$$
\sigma_{p q}^{0}=\sigma_{c p q}^{0}+T^{2} \sigma_{s p q}^{0}
$$

whereas the canopy part $\sigma_{c_{p q}}^{0}$ in linear scale and the two-way attenuation $T_{p q}^{2}$ are written as

$$
\begin{aligned}
\sigma_{c_{p q}}^{0} & =A_{p q} V_{1} \cos \theta\left(1-T_{p q}^{2}\right), \\
T_{p q}^{2} & =e^{-2 B_{p q} V_{2} \sec \theta},
\end{aligned}
$$

where $\theta$ is the local incidence angle, $V 1$ and $V 2$ are empirical vegetation descriptors, and $A_{p q}$, as well as $B_{p q}$, are fitted parameters of the model which depend on the vegetation properties and the radar configuration. For $\sigma_{s_{p q}}^{0}$ in Equation (27), each of the described surface models in Section 3.1 can be used.

\subsubsection{Semi-Empirical Single Scattering Radiative Transfer (SSRT) Model}

The SSRT model used by De Roo [35] and Ulaby [17] is a semi-empirical first-order scattering model. The model is defined as

$$
\sigma_{p q}^{0}=\sigma_{g p q}^{0}+\sigma_{c_{p q}}^{0}+\sigma_{c g t_{p q}}^{0}+\sigma_{g c g_{p q}}^{0}
$$

where

$$
\sigma_{g p q}^{0}=T_{p} T_{q} \sigma_{s p q}^{0}
$$

with $T_{p}$ and $T_{q}$ as attenuation of the canopy for different polarizations and $\sigma_{s_{p q}}^{0}$ describing the pure surface scattering mechanism. Similar to the definition of WCM in Section 3.2.1, all surface models described in Section 3.1 can be used for calculating the surface contribution $\sigma_{s p q}^{0}$ within SSRT. Furthermore, the $p$ polarized one way transmittivity of the canopy $T_{p}$ is defined as

$$
T_{p}=e^{-\tau_{p}},
$$

with $\tau_{p}$ as the $p$ polarized attenuation of the canopy given by

$$
\tau_{p}=k_{e}^{p} H \sec \theta,
$$

whereas $H$ represents the canopy height. The extinction coefficient $k_{e}^{p}$ which accounts for the absorption and scattering losses of the electromagnetic wave through the canopy is defined as

$$
k_{e}^{p}=k_{a}^{p}+k_{s}^{p} .
$$

In general, a canopy consists of leaves, stalks, and branches with different shapes and orientations, which do not show a linear distribution in the vertical. However, in the applied SSRT, it is assumed 
that $k_{e}^{p}, k_{a}^{p}$, and $k_{s}^{p}$ follow a uniform distribution in the vertical as a function of $\mathrm{z}$ within the canopy layer. In addition to the extinction coefficient, the scattering part $k_{s}^{p}$ of $k_{e}^{p}$ can be derived by

$$
k_{s}^{p}=k_{e}^{p} \omega,
$$

where $\omega$ represents the single scattering albedo. For the direct backscattering contribution of the canopy $\sigma_{c_{p q}}^{0}$, Attema and Ulaby's [22] water cloud approach of identical scatterers, which are uniformly distributed within the volume, is used. Thus, multiple scattering effects are ignored. As a consequence, the volume backscattering coefficient $\sigma_{V_{p q}}^{\text {back }}$ of the vegetation medium is defined as

$$
\sigma_{V_{p q}}^{b a c k}=N_{v} \sigma_{p q}^{b a c k}
$$

with $N_{v}$ as the number of scattering particles per unit volume and $\sigma_{p q}^{b a c k}$ as the $p q$ polarized backscattering cross section of a single particle. Finally, the $p q$ polarized canopy backscattering coefficient $\sigma_{\mathcal{c}_{p q}}^{0}$ within Equation (30) can be obtained from

$$
\sigma_{c_{p q}}^{0}=\frac{\sigma_{V_{p q}}^{\text {back }} \cos \theta}{k_{e}^{p}+k_{e}^{q}}\left(1-T_{p} T_{q}\right) .
$$

Furthermore, ground/canopy $\left(\sigma_{g c_{p q}}^{0}\right)$ and canopy/ground $\left(\sigma_{c g_{p q}}^{0}\right)$ scattering contributions are defined as

$$
\begin{aligned}
\sigma_{g c_{p q}}^{0} & =\sigma_{v_{p q}}^{b i s t} H R_{q} T_{p} T_{q}, \\
\sigma_{c g_{p q}}^{0} & =\sigma_{v_{p q}}^{b i s t} H R_{p} T_{p} T_{q},
\end{aligned}
$$

where $H$ is the canopy height, $\sigma_{v_{p q}}^{b i s t}$ is the bi-static scattering cross section of a single leaf or stalk, and $R_{p}$ describes the $p$ polarized Fresnel reflectivity (Equations (6) and (7)). Thus, the total canopy ground contribution $\sigma_{c g t_{p q}}^{0}$ within Equation (30) as the sum of $\sigma_{g c_{p q}}^{0}$ and $\sigma_{c g p q}^{0}$ can be written as

$$
\sigma_{c g t p q}^{0}=\sigma_{v_{p q}}^{b i s t} H\left[R_{p}+R_{q}\right] T_{p} T_{q} .
$$

Furthermore, ground canopy ground contribution $\left(\sigma_{g c g_{p q}}^{0}\right)$ within Equation (30) is defined as

$$
\sigma_{g c g_{p q}}^{0}=\frac{\sigma_{V_{p q}}^{b a c k} \cos \theta}{k_{e}^{p}+k_{e}^{q}}\left(R_{p} R_{q}-T_{p} T_{q}\right)
$$

\subsection{Practical Considerations}

Each described model requires a different set of input parameters. A summary for the different RT models is given in Table 4. For some parameters, field measurements (Section 2.2) or literature values (s and $\omega$, Table 5) are used, and other site dependent parameters have to be fitted. The analyzed wheat fields were sown in autumn of 2016. By the starting point of the observation period (end of March 2017), the soil surface was already smoothed out by rain and the ground was covered by wheat plants (height $>10 \mathrm{~cm}$ ). Marzahn et al. [72] showed that, for wheat fields with the above mentioned state, only minor changes in terms of roughness throughout the vegetation period are observable. Previous studies regarding periodic features and roughness changes $[73,74]$ found out that changes in surface roughness due to soil rows as periodic feature within wheat fields are essential if the viewing angle is nearly perpendicular to the row orientation, but, for other viewing angles, the changes within surface roughness are negligible. The viewing angle and the row orientation of the wheat fields in our study are always $<75^{\circ}$. Therefore, changes due to periodic soil rows are assumed to be negligible. Typical roughness measurements of various winter wheat fields suggest rms values between 1.0 and 
$1.3[72,73,75-78]$. With the assumption of only minor roughness changes throughout the vegetation period, a literature value for surface height $s$ of $1.2 \mathrm{~cm}$ was chosen. The value of $1.2 \mathrm{~cm}$ was used due to former field campaign measurements of wheat fields in Germany [72,73]. For single scattering albedo $\omega$, a common literature value of 0.03 [79] was set. The conversion from soil moisture field measurements to the required model input of dielectric constant $\epsilon$ for models Oh92, Dubois95, and IEM was performed by using a dielectric mixing model for soils after Dobson et al. [80]. The required soil information about sand and clay content, bulk density (Table 2), and soil moisture (Table 1) were provided by field measurements and laboratory results. Additionally, for some parameters, in their original form, adjustments were made within this study. In particular, DeRoo et al. [35] used for parameterizing of the extinction coefficient $k_{e}^{p}$ a combination of an empirical parameter, vegetation water mass and vegetation height. In our study, the vegetation water mass, and the vegetation height were replaced by total LAI. Therefore, $k_{e}^{p}$ is defined by

$$
k_{e}^{p}=\operatorname{coef} * \sqrt{L A I},
$$

with coef as an empirical parameter. To reduce the required parameters for model IEM, a well-established approach of Baghdadi et al. [31,45] was used. The correlation length $L$ was replaced by a fitted parameter Lopt which is dependent on $s, \theta$, and the polarization. Lopt for C-band $V V$ polarization data and the Gaussian correlation function after Baghdadi et al. [45] is defined as

$$
\operatorname{Lopt}(s, \theta, V V)=1.281+0.134(\sin 0.19 \theta)^{-1.59 s} .
$$

The refined version of Baghdadi is hereinafter referred to as IEM_B. A schematic illustration of the RT model calibration approach is shown in Figure 3. All RT model combinations (surface + canopy) are driven by field measurements and the required empirical parameters (Table 4). The fitting of the empirical parameters was carried out by minimizing the sum of the squared error between modeled and measured (Sentinel-1) radar backscatter values. For the measured Sentinel-1 backscatter value of each measurement point shown in Figure 1, the mean backscatter of $5 \times 5$ pixel $(50 \times 50 \mathrm{~m})$ around the measurement location was chosen. In a first fitting approach, all parameters shown in Table 4 were defined to be static for the entire vegetation period. In a second fitting approach, WCM parameters $C, D$, and $A$ were set to be static; therefore, the mean (Table 5) of all model results of the static approach was used. The used values for the different parameters for validation are shown in Table 5. Additionally, the attenuation of the backscatter through the canopy was defined to be variable throughout the time series. More specifically, parameters coef within SSRT and $B$ within WCM were fitted for each time step individually by taking three observations before and after into account. By making only coef or $B$ variable, changes within the results can then clearly related to changes of the attenuation of the radar backscatter signal by the canopy. Field measurements used as model input parameters show multidimensionally unstructured inter- and intra-field correlations. Therefore, measurement point independency is assumed, and a validation of the parametrized RT models is performed using a leave-one-out cross-validation approach. Hereby, the parameter mean of the calibration results of eight measurement points is validated with the remaining measurement point. 
Table 4. Overview of differences of surface models Water Cloud Model (WCM surface), Oh models Oh92 and Oh04, Dubois95, and Integral Equation Model refined version of Baghdadi (IEM_B), as well as canopy models Single Scattering Radiative Transfer (SSRT) and WCM canopy, in terms of type, validity range, site dependency, required input parameters, and polarization. Separation of used input parameter of the analyzed Radiative Transfer (RT) models in fitted parameters and parameters where field measurements or literature values were used as input data.

\begin{tabular}{|c|c|c|c|c|c|c|}
\hline & \multirow[b]{2}{*}{ Type } & \multirow[b]{2}{*}{ Validity Range } & \multirow{2}{*}{$\begin{array}{c}\text { Site } \\
\text { Dependent }\end{array}$} & \multicolumn{2}{|c|}{ Required Parameters } & \multirow[b]{2}{*}{ Pol. } \\
\hline & & & & Fitted & $\begin{array}{l}\text { Field Measurements } \\
\text { or Literature Values }\end{array}$ & \\
\hline $\begin{array}{l}\mathrm{WCM} \\
\text { surface }\end{array}$ & empi. & $10^{\circ}<\theta<70^{\circ}$ & Yes & $C, D$ & $\theta, m v$ & $\begin{array}{c}\mathrm{HH}, \mathrm{VV} \\
\mathrm{VH}\end{array}$ \\
\hline Oh92 & semi-empi. & $\begin{array}{c}10^{\circ}<\theta<70^{\circ} \\
0.1<k s<6 \\
9<m v<31 \text { Vol } \%\end{array}$ & No & & $\begin{array}{c}s, k, \theta, \epsilon \\
(\text { clay, sand, bulk, mv) }\end{array}$ & $\begin{array}{c}\mathrm{HH}, \mathrm{VV} \\
\mathrm{VH}\end{array}$ \\
\hline Oh04 & semi-empi. & $\begin{array}{c}10^{\circ}<\theta<70^{\circ} \\
0.13<k s<6.98 \\
4<m v<29.1 \text { Vol. } \%\end{array}$ & No & & $s, k, \theta, m v$ & $\begin{array}{c}\mathrm{HH}, \mathrm{VV} \\
\mathrm{VH}\end{array}$ \\
\hline Dubois95 & semi-empi. & $\begin{array}{c}30^{\circ}<\theta<60^{\circ} \\
k s \leq 2.5 \\
m v \leq 35 \mathrm{Vol} . \%\end{array}$ & No & & $\begin{array}{c}s, k, \theta, \epsilon \\
(\text { clay, sand }, \text { bulk, } m v)\end{array}$ & $\mathrm{HH}, \mathrm{VV}$ \\
\hline IEM_B & theoretical & $\begin{array}{c}10^{\circ}<\theta<70^{\circ} \\
k s \leq 3\end{array}$ & No & & $\begin{array}{c}s, k, l, \theta, \epsilon \\
(\text { clay, sand, bulk, mv) }\end{array}$ & $\begin{array}{c}\mathrm{HH}, \mathrm{VV} \\
\mathrm{VH}\end{array}$ \\
\hline SSRT & semi-empi. & & Yes & $k e$ (coef) & $H, L A I, \theta, \omega$ & $\begin{array}{c}\mathrm{HH}, \mathrm{VV} \\
\mathrm{VH}\end{array}$ \\
\hline $\begin{array}{l}\text { WCM } \\
\text { canopy }\end{array}$ & empi. & & Yes & $A, B$ & $V 1(L A I), V 2(L A I), \theta$ & $\begin{array}{c}\mathrm{HH}, \mathrm{VV} \\
\mathrm{VH}\end{array}$ \\
\hline
\end{tabular}

Table 5. Used model input parameters for validation.

\begin{tabular}{cccccc}
\hline $\begin{array}{c}k \\
{\left[\mathrm{~cm}^{-1}\right]}\end{array}$ & $\begin{array}{c}s \\
{[\mathbf{c m}]}\end{array}$ & $\omega$ & $\begin{array}{c}C \\
{[\mathrm{~dB}]}\end{array}$ & $\begin{array}{c}D \\
{[\mathrm{~dB}]}\end{array}$ & $A$ \\
\hline 1.13 & 1.2 & 0.03 & -14.61 & 12.88 & 0.0029 \\
\hline
\end{tabular}

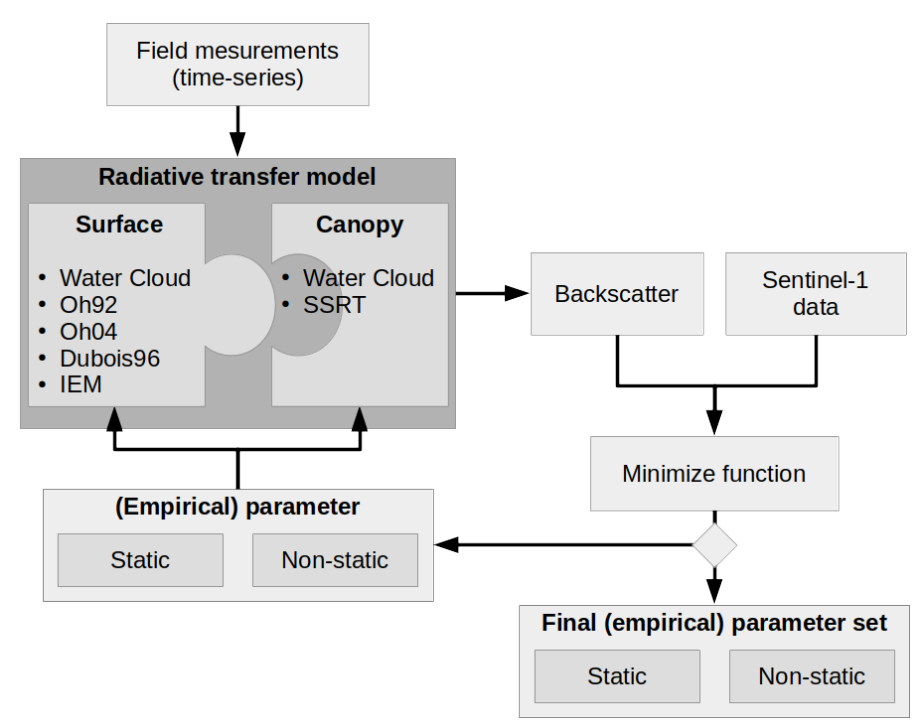

Figure 3. Schematic illustration of RT model calibration approach.

\subsection{Differences Between Applied Models}

WCM is a purely empirical model and depends, therefore, only on the calibrated empirical coefficients. It is applicable under almost all surface/vegetation conditions, but it has to be calibrated 
for different test sites separately. The transferability to other test sites and or other surface/vegetation conditions is not possible. Surface models, like Oh92, Oh04, Dubois95, and IEM, were originally only developed for bare soil and or sparse vegetation conditions. Nevertheless, different studies replaced the surface component within WCM and SSRT with Oh [17,35,43,47], Dubois95 [51,54,55], or IEM/IEM_B $[17,45,53]$ models. One key advantage of the semi-empirical-based (Oh92, Oh04, Dubois95) or theoretical-based (IEM/IEM_B) surface models in comparison to WCM is their better transferability to other test sites and surface/vegetation conditions. Models, like Oh92, Oh04, or Dubois95, are based on a hybrid construction with experimental data guided by trends predicted by theoretical models [17]. Theoretical models, like IEM/IEM_B, on the other hand, have a theoretical foundation, whereas, for used mathematical approximations within the model, various assumptions to retrieve a analytical solution are made [17]. The Oh model of 1992 was developed based on a single experiment with information about only four different soil surfaces [26]. For the model version of 2004, Oh used information of approximately 40 bare soil fields conducted over seven experiments [27]. Furthermore, the usage of $\epsilon$ and $R$ in model Oh92 was refined to the usage of $m v$ in model Oh04. Model Dubois95 is the only model which was developed only for co-polarized backscatter data (HH or VV), whereas the other models can calculate co- and cross-polarized backscatter values ( $\mathrm{HH}, \mathrm{VH}, \mathrm{VV})$. Differences between vegetation models WCM and SSRT exists in the form of their simplicity. WCM calculates only the volume backscattering component, whereas, within SSRT, additional backscatter components, such as plant-ground and ground-plant interaction, as well as ground-plant-ground scattering contributions, are considered. In our implementation, the vegetation descriptor of WCM is LAI, whereas the vegetation descriptor of SSRT consists of LAI and canopy height. In general, the computational time and the required additional input parameters are increasing from empirical to semi-empirical and theoretical models. A summary of the different models with information about type, validity range, site dependency, required parameters, and used polarization are given in Table 4.

\section{Results and Discussion}

\subsection{Model Calibration Results}

\subsubsection{Static Empirical Parameters}

In a first calibration approach, the empirical parameters for the different models were treated as static throughout the entire time series. The modeled backscatter was then compared to the measured backscatter from Sentinel-1. Table 6 shows the mean of RMSE and $R^{2}$ of all analyzed sample points (Figure 1) for different surface and canopy model combinations. The retrieved RMSE of the calibration results ranges from 1.92 to $2.25 \mathrm{~dB}$ with $\mathrm{R}^{2}$ of 0.08 to 0.34 , respectively. A more detailed picture regarding differences between modeled and Sentinel-1 backscatter during the time series is shown for field 508 in Figure 4. While, for the first half of the vegetation period, all model combinations show a relatively good fit to Sentinel-1 backscatter data, in the second half, deviations are obvious. Furthermore, from the beginning of June where LAI reaches its saturation point and the maximum plant height is almost reached, no significant change over time within the modeled backscatter can be observed. The analyzed soil models (different colors) show small differences, whereas a clear separation between analyzed canopy models (solid vs dashed lines), especially for later vegetation stages, is noticeable. As described in Section 2.3, Sentinel-1 data of four different overpasses, and therefore with different incidence and azimuth angles, were used for this analysis. In Figure 4, every fourth point (same icon) of the Sentinel-1 backscatter time series represents the same satellite acquisition geometry (same incidence and azimuth angle). The incidence angle is implemented within the used RT models, whereas the models do not account for difference azimuth angles. The black line (Sentinel-1 backscatter) in Figure 4 shows that the observed backscatter values differ with varying incidence angles and changes in soil moisture. The model predictions (different colors) illustrates that the models can account for varying incidence angles and changes in soil moisture only until the end of May. Furthermore, the good correlation of modeled and Sentinel-1 backscatter values suggests 
that the effect of different azimuth angles on backscatter values seems to be negligible until the end of May. The main change within the wheat fields in June and July in terms of phenology are the flowering, the development of the fruit, and, later on, the ripening [75,81]. For these phenology stages, the increase in backscatter is caused by higher sensitivity of the radar signal to the ground contribution due to water loss within the vegetation [81]. Mattia et al. [76] identified the heading period as turning point where the sensitivity of the radar backscatter to above-ground biomass decreases, whereas the sensitivity to soil surface increases. The temporal evolution of modeled ground contribution to the total backscatter for different model combinations (different colors) with the observed Sentinel-1 total backscatter (black line) is shown in Figure 5 (top part). Until the increase in canopy height at the beginning of May (Table 4), the modeled ground scattering part seems to be the main contributor to the total backscatter, whereas the canopy part is negligible. With increase, especially in canopy height, the ground contribution drops significantly. The expected decrease in backscatter of the ground contribution due to a bigger canopy layer (increase of canopy height and LAI) can be more clearly observed for SSRT than WCM. The differences between SSRT and WCM might be found by using different canopy descriptors (SSRT: LAI and canopy height; WCM: LAI). Differences in ground contributions between Dubois95 and the other surface models are related to differences in the modeled attenuation through the canopy $T$ (Figure 4, bottom part). $T$ is regulating the contribution intensity of the ground and canopy part for the total backscatter calculation. The temporal evolution of $T$ with a value range from 0 (dominant canopy contribution) to 1 (dominant ground contribution) is shown in Figure 5 (bottom part). All model combinations show a similar temporal shape with slightly higher values for model Dubois95. $T$ decreases from April (dominant ground contribution) to mid-May (dominant canopy contribution) and stays at its minimum after mid-May. The expected increase $[76,81]$ of the modeled ground contribution due to higher ground sensitivity in June and July (phenology: flowering, development of the fruit, and ripening) is not observed within the modeled data. In our case, $T$ is mainly driven by static empirical parameter $B$ (WCM) and coef (SSRT), as well as non-static vegetation descriptors LAI and/or canopy height. Therefore, with almost no changes in LAI and canopy height in June and July (Figure 4, middle part), the two-way attenuation $T$ stays near zero, which indicates a dominant canopy model contribution to the total backscatter calculation. By definition, LAI is defined as the one-sided leaf area per measured ground unit [82]. By the time wheat plants reach their maximum height, the leaves are fully developed. Changes within the wheat plants, especially during vegetation stages of flowering, fruit development, or ripening (Figure 4), are based mainly on increasing biomass within grains and stems, as well as changes of the vegetation water content. However, biomass changes in grains and stems, as well as vegetation water content loss, especially during the ripening stage, are not reflected within the LAI. Therefore, almost no information about the increased biomass and the water loss due to ripening of the plants is given within this model configuration. Plant moisture reduction affects the attenuation of the radar signal by the canopy in a way that the canopy is more transparent for the radar wave [83]. Therefore, the sensitivity of the radar signal to the canopy should decrease, whereas the sensitivity to the surface increases. The almost non-existent deviation between Sentinel-1 and modeled backscatter in early vegetation stages suggests that the interaction between surface and canopy model, and therefore the attenuation of the backscatter signal by the canopy, described by static empirical parameters and LAI, can be modeled sufficiently only in early vegetation stages. For good backscatter model results during later vegetation stages, the backscatter changes due to water loss within the plants have to be considered. The effects of utilizing non-static empirical parameters to account for these shortcomings are discussed in the next sections. 
Table 6. Calibration results of different model combinations with static empirical parameters. Mean RMSE, ubRMSE, and $\mathrm{R}^{2}$ of all analyzed field measurement points.

\begin{tabular}{ccc}
\hline Model & \multicolumn{2}{c}{ Calibration } \\
Surface + Canopy & RMSE [dB] & R $^{2}$ \\
\hline Oh92 + SSRT & 2.11 & 0.20 \\
Oh92 + WCM & 1.97 & 0.26 \\
Oh04 + SSRT & 2.02 & 0.18 \\
Oh04 + WCM & 1.92 & 0.23 \\
Dubois95 + SSRT & 2.09 & 0.08 \\
Dubois95 + WCM & 2.03 & 0.08 \\
WCM + SSRT & 2.25 & 0.22 \\
WCM + WCM & 2.08 & 0.34 \\
IEM_B + SSRT & 2.24 & 0.15 \\
IEM_B + WCM & 2.13 & 0.24 \\
\hline
\end{tabular}

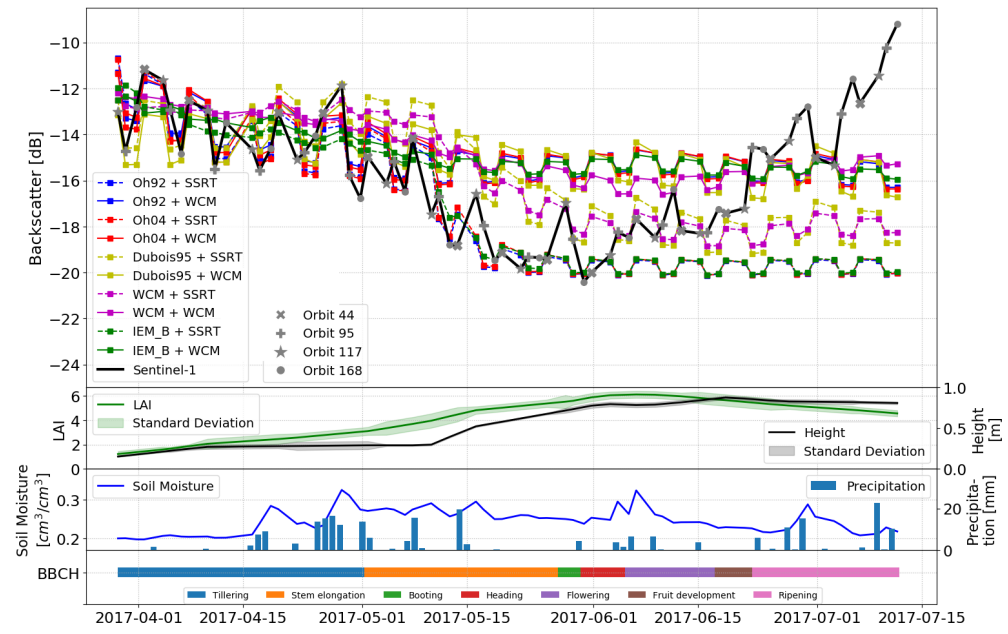

Figure 4. Measured and modeled data (static parameters) of wheat field 508 for vegetation period 2017. VV-polarized backscatter comparison of different model combinations (surface + canopy) with static empirical parameters and Sentinel-1 data. Different icons represent different acquisition geometries of Sentinel-1 (top). Field measurements of Leaf Area Index (LAI), canopy height, and soil moisture, as well as precipitation data from meteorological station Freising (middle). Observed vegetation phenology according to BBCH scale [84] (bottom).

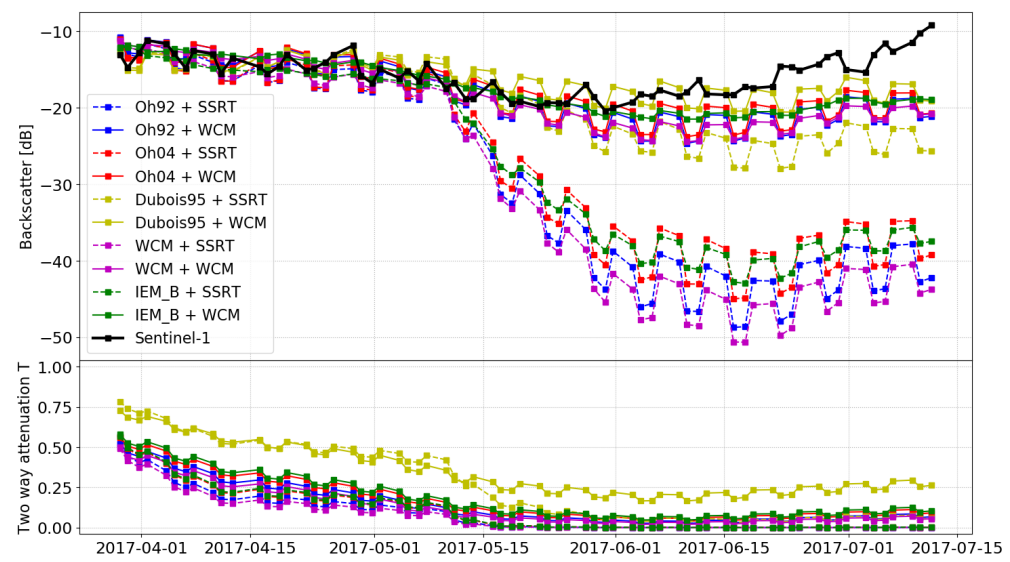

Figure 5. Model results (wheat field 508, static parameter) of ground contribution to total backscatter for different model combinations (different colors) with Sentinel-1 VV polarized total backscatter (black line) as reference (top). Temporal evolution of model component two way attenuation by the canopy $T$ (bottom). 


\subsubsection{Non-Static Empirical Parameters}

Due to the results in Section 4.1.1, which showed that LAI and height cannot account for the observed backscatter changes in June and July (increase of Sentinel-1 backscatter), a second calibration approach with non-static empirical parameter where chosen. As already mentioned, the observed increase in backscatter is caused by a higher sensitivity of the radar signal to the ground contribution. The attenuation of the backscatter $T$, more precisely $B$, for WCM and coef for SSRT were identified as the main drivers for the increase or decrease of the ground contribution; therefore, a non-static approach for these parameters was tried. The other empirical parameters of WCM (surface: C, D; canopy: A) were set as static values (mean of the retrieved static values during the calibration approach shown in Section 4.1.1) to clearly relate the observed changes to the attenuation of the backscatter. The modeled backscatter was compared to Sentinel- 1 observations and the statistics for different model combinations are shown in form of mean RMSE and $\mathrm{R}^{2}$ of all analyzed field measurement points in Table 7. The retrieved RMSE ranges from 1.13 to $1.60 \mathrm{~dB}$ with $R^{2}$ of 0.45 to 0.82 , respectively. By comparing different model combinations, almost no differences between the two analyzed canopy models can be observed. A different picture is shown by comparing surface models only. WCM seems to outperform all others, whereas differences between WCM and Oh92, Oh04, and IEM_B are smaller than differences of these models to Dubois95. Similar to the approach with static empirical parameters, the evolution over time of modeled and Sentinel-1 backscatter is shown in Figure 6 for one measurement point of field 508. Like the results in Section 4.1.1, modeled backscatter results of the first half of the vegetation period fit well to the observed Sentinel-1 backscatter data. Contrary to the static parameter approach, the second half of the vegetation period shows high correlations between Sentinel-1 and modeled backscatter. Unlike the results of the static approach (Figure 5, top part), the expected increase of the ground contribution at the end of the vegetation period can be observed in Figure 7 (top part). The increase of the ground contribution to the total backscatter is also reflected within the two-way attenuation by the canopy $T$ shown in Figure 7 (bottom part). Compared to the static approach (Figure 5, bottom part), the values of $T$ from April to the beginning of June are very similar for all model combinations, except Dubois95. The temporal changes of non-static parameters $B$ and coef are shown for the validation results in Figures 8 and 9 and will be further discussed in the validation Section 4.2. Besides the modeled backscatter increase for the second half of the vegetation period, different trends between Sentinel-1 and modeled backscatter for individual time steps are observed. This mismatch might occur for several reasons. As already mentioned in Section 4.1.1, Sentinel-1 data with different incidence and azimuth angles were used. A closer look at every fourth modeled point (same incidence and azimuth angle) in Figure 6 (same icon) shows a steady increase of modeled backscatter values at the end of the vegetation period. Therefore, an overall trend of an increasing backscatter can be seen for Sentinel-1 and modeled data. Due to non contradictory trends during the first half of the vegetation period, it seems that the influence on backscatter due to incidence and azimuth angles increases for the second half of the vegetation period. Thus, higher canopy heights and LAI values may also increase the impact of different incidence and azimuth angles on the backscatter behavior. In addition, the acquisition time (Table 3) of the Sentinel-1 images might play another role for different attenuation effects by the canopy [81]. The acquisition time of the satellite differs for different overpasses. For the MNI test site, Sentinel- 1 data was acquired during early morning or late afternoon (Table 3). This might lead to differences in the observations due to dew $[85,86]$ or different plant alignments towards the sun which, in theory, leads to different backscatter attenuations through the canopy [87-89], which are not accounted for within the models. Despite the different trends during the temporal evolution of modeled and Sentinel-1 backscatter for the second half of the vegetation period, the observed overall increase in backscatter at the end of the vegetation period can be modeled well. 
Table 7. Calibration and validation results of different model combinations with non-static empirical parameters. Mean RMSE, ubRMSE, and $\mathrm{R}^{2}$ of all analyzed field measurement points.

\begin{tabular}{cccccc}
\hline $\begin{array}{c}\text { Model } \\
\text { Surface + Canopy }\end{array}$ & \multicolumn{2}{c}{ Calibration } & \multicolumn{3}{c}{ Validation } \\
RMSE [dB] & $\mathbf{R}^{2}$ & RMSE [dB] & ubRMSE [dB] & $\mathbf{R}^{2}$ \\
\hline Oh92 + SSRT & 1.24 & 0.73 & 2.82 & 2.10 & 0.59 \\
Oh92 + WCM & 1.22 & 0.73 & 2.75 & 2.21 & 0.57 \\
Oh04 + SSRT & 1.33 & 0.69 & 2.87 & 2.14 & 0.57 \\
Oh04 + WCM & 1.32 & 0.68 & 2.81 & 2.22 & 0.57 \\
Dubois95 + SSRT & 1.55 & 0.49 & 3.06 & 2.11 & 0.49 \\
Dubois95 + WCM & 1.60 & 0.45 & 3.06 & 2.18 & 0.48 \\
WCM + SSRT & 1.16 & 0.82 & 2.65 & 1.93 & 0.63 \\
WCM + WCM & 1.13 & 0.81 & 2.57 & 2.08 & 0.60 \\
IEM_B + SSRT & 1.32 & 0.78 & 2.62 & 1.82 & 0.64 \\
IEM_B + WCM & 1.34 & 0.77 & 2.54 & 1.92 & 0.62 \\
\hline
\end{tabular}

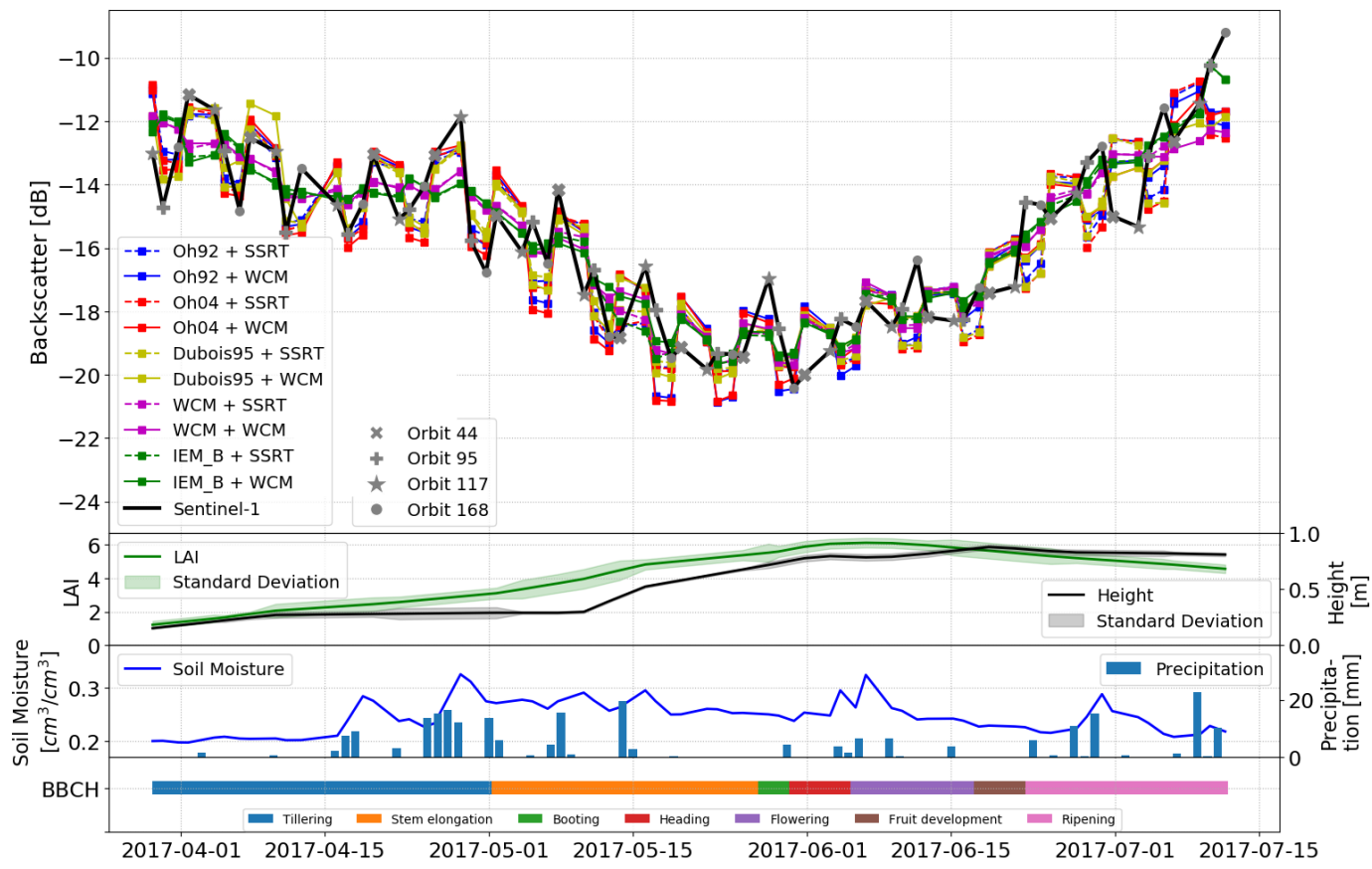

Figure 6. Measured and modeled data (non-static parameters) of wheat field 508 for vegetation period 2017. VV-polarized backscatter comparison of different model combinations (surface + canopy) with non-static empirical parameters and Sentinel-1 data. Different icons represent different acquisition geometries of Sentinel-1 (top). Field measurements of LAI, canopy height, and soil moisture, as well as precipitation data from meteorological station Freising (middle). Observed vegetation phenology according to BBCH scale [84] (bottom). 


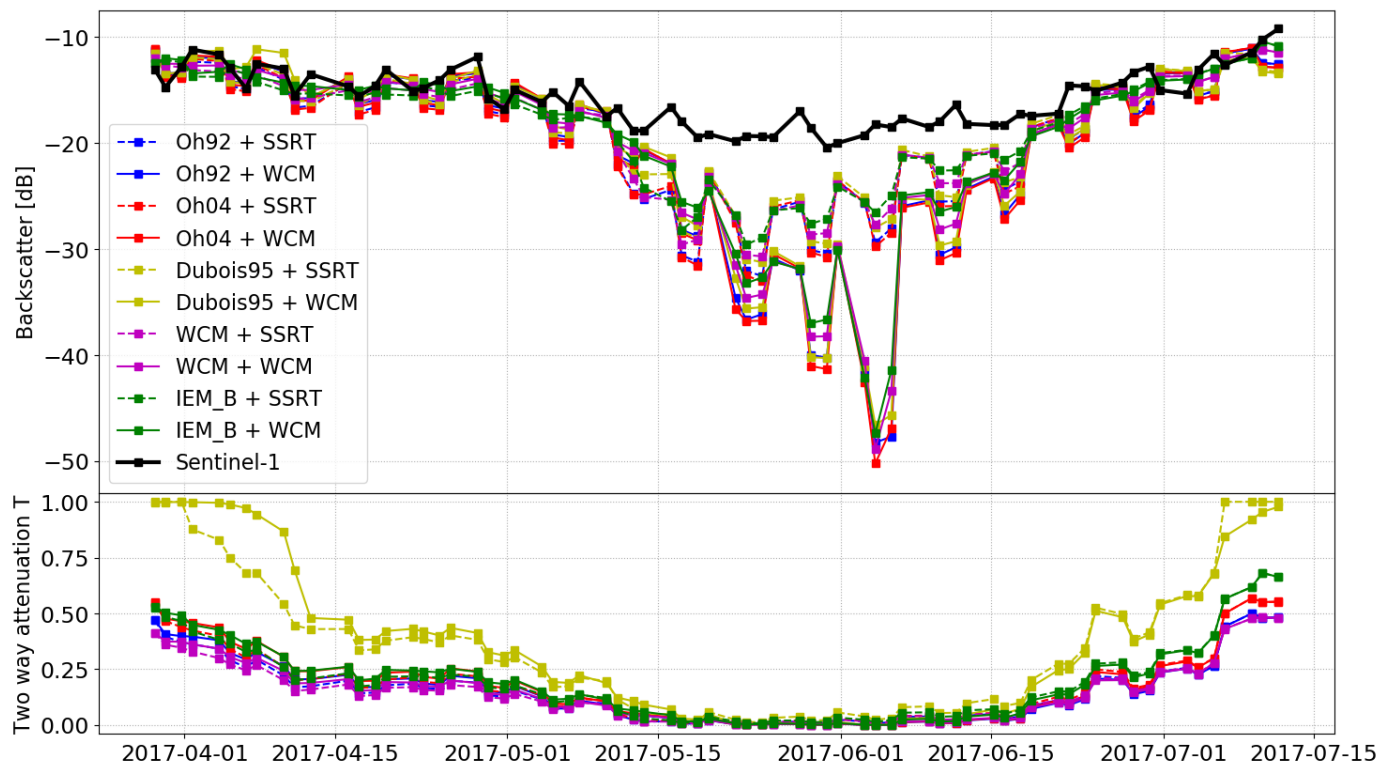

Figure 7. Model results (wheat field 508, non-static parameter) of ground contribution to total backscatter for different model combinations (different colors) with Sentinel-1 VV polarized total backscatter (black line) as reference (top). Temporal evolution of model component two way attenuation by the canopy $T$ (bottom).

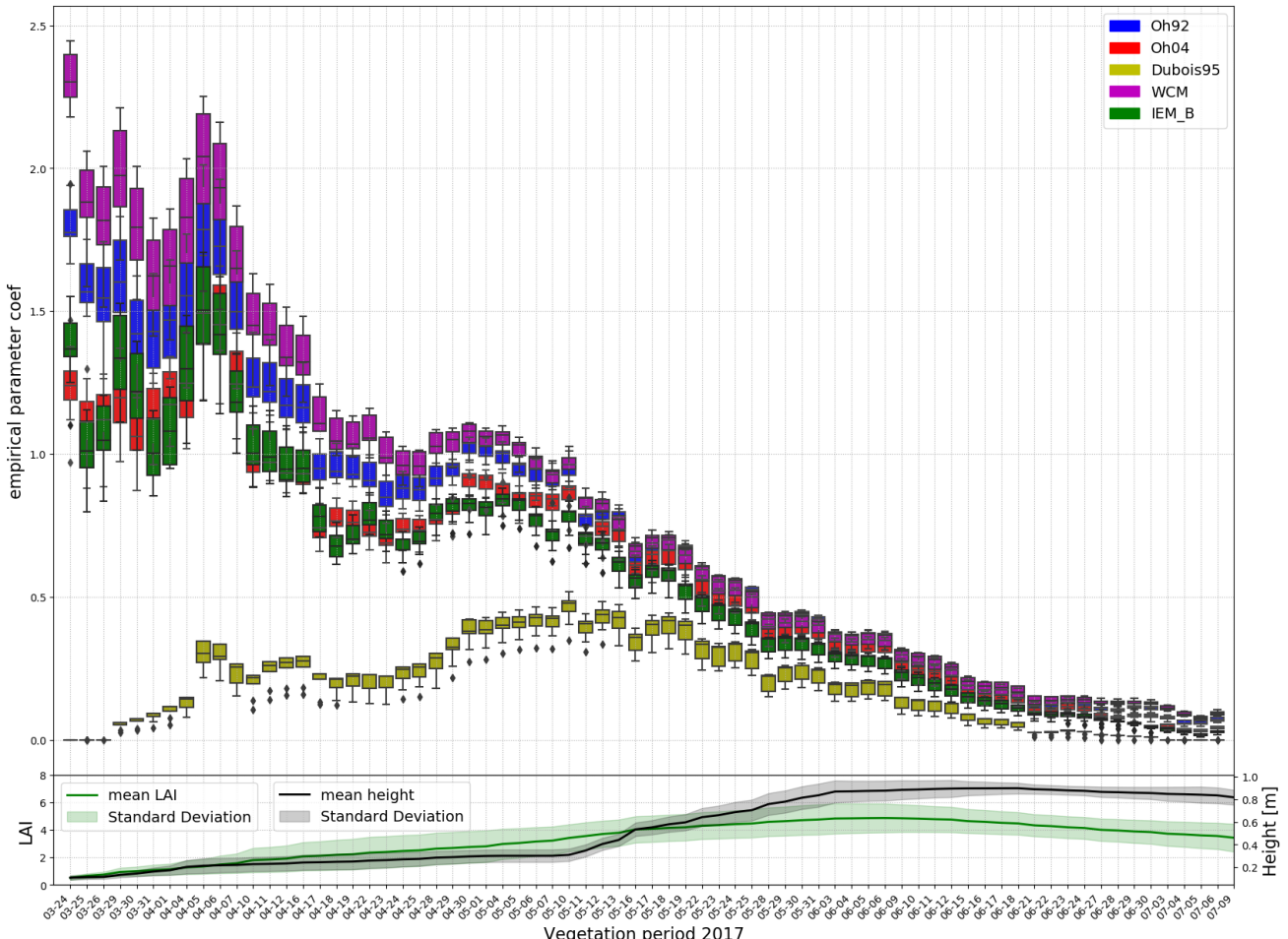

Figure 8. Evolution over time of non-static parameter coef separated by different surface models (colors) for each Sentinel-1 acquisition date during vegetation period 2017. The box plots show the range of coef used during the validation approach for different fields point (top). Mean and standard deviation of all measurement points for LAI and canopy height (bottom). 


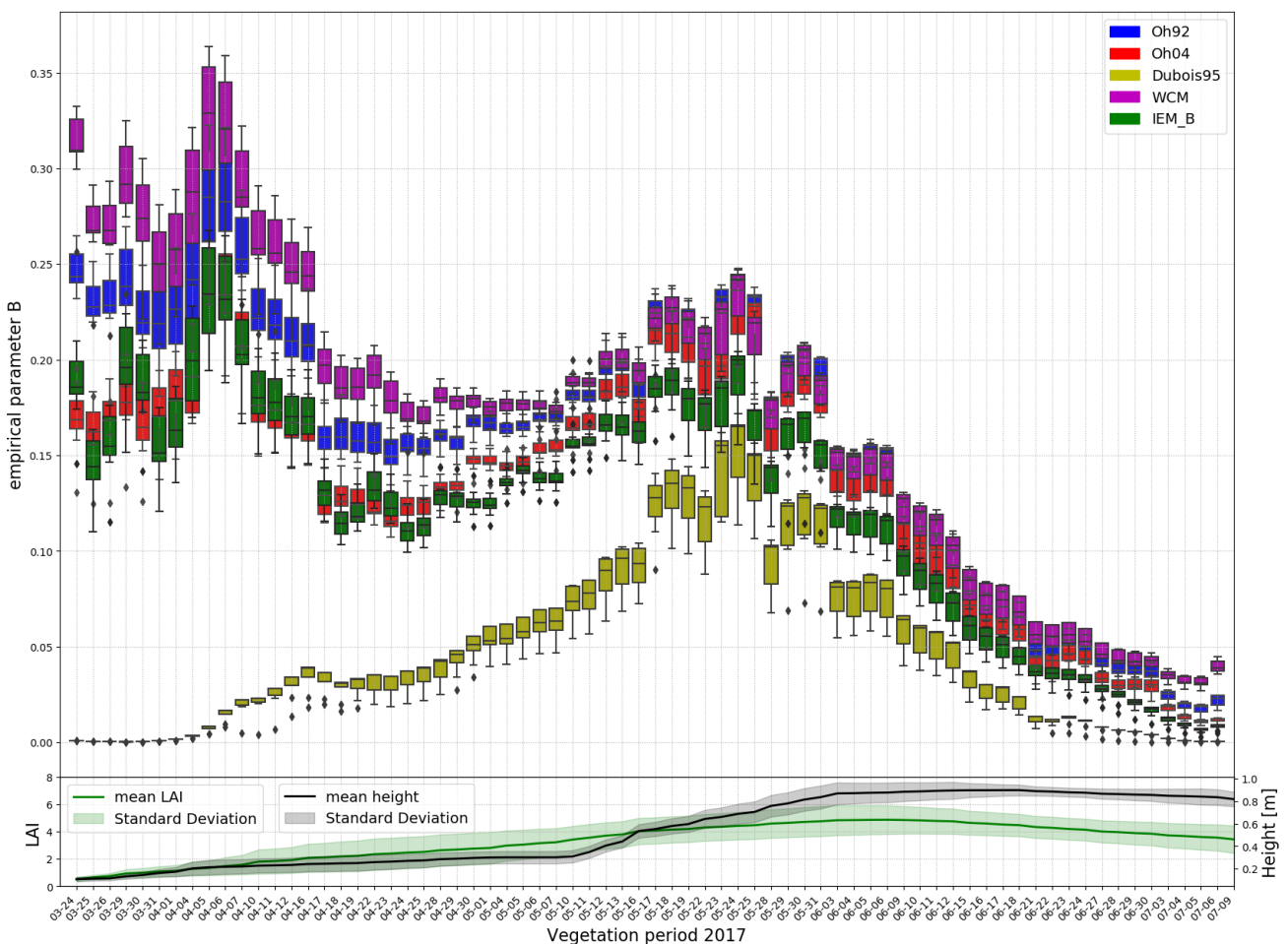

Figure 9. Evolution over time of non-static parameter $B$ separated by different surface models (colors) for each Sentinel-1 acquisition date during vegetation period 2017. The box plots show the range of $B$ used during the validation approach for different fields point (top). Mean and standard deviation of all measurement points for LAI and canopy height (bottom).

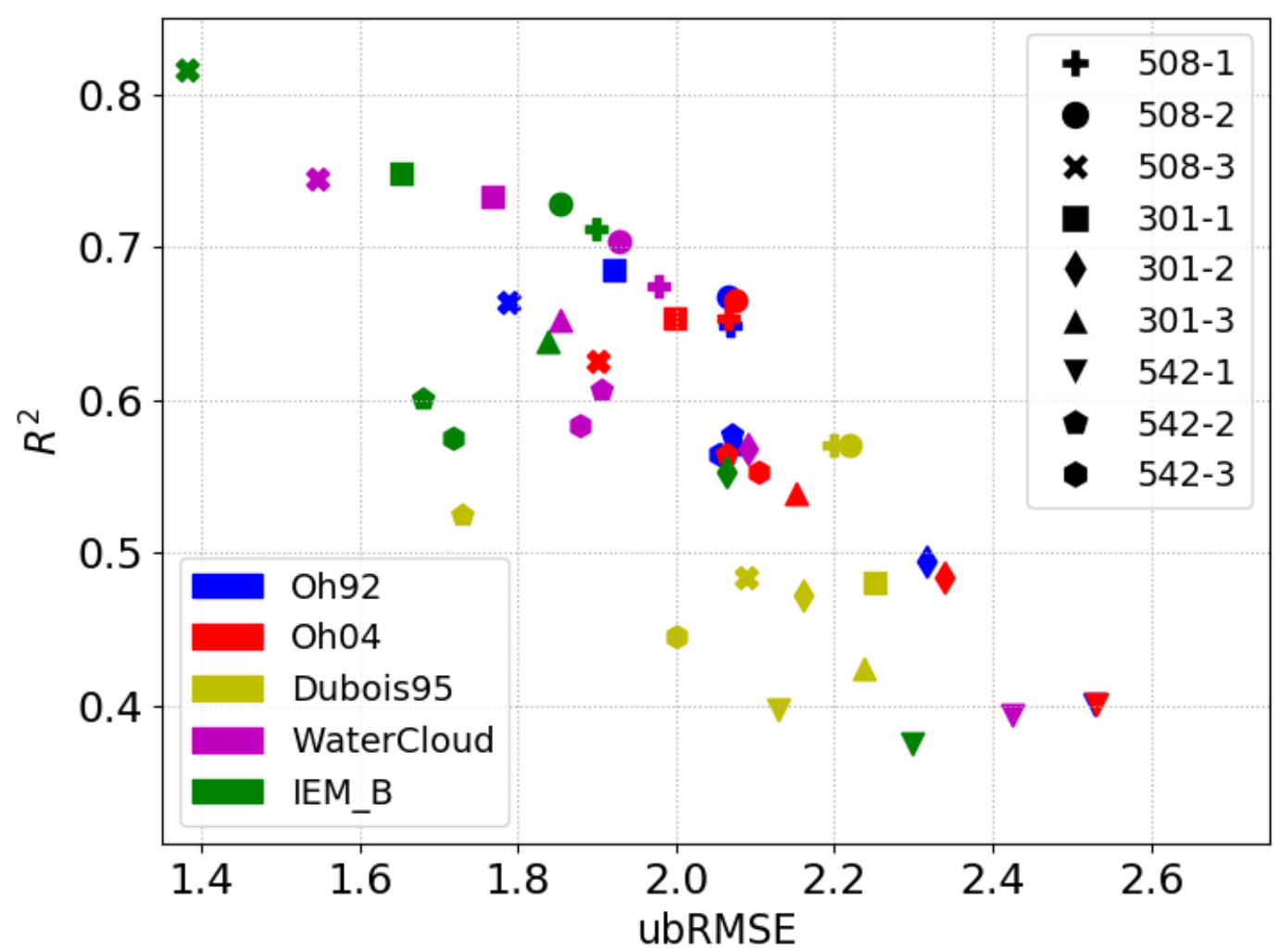

Figure 10. Scatter plot showing statistical validation results (correlation coefficient $\mathrm{R}^{2}$ and ubRMSE) for canopy model SSRT separated by different surface models (colors) and different field points (icons). 


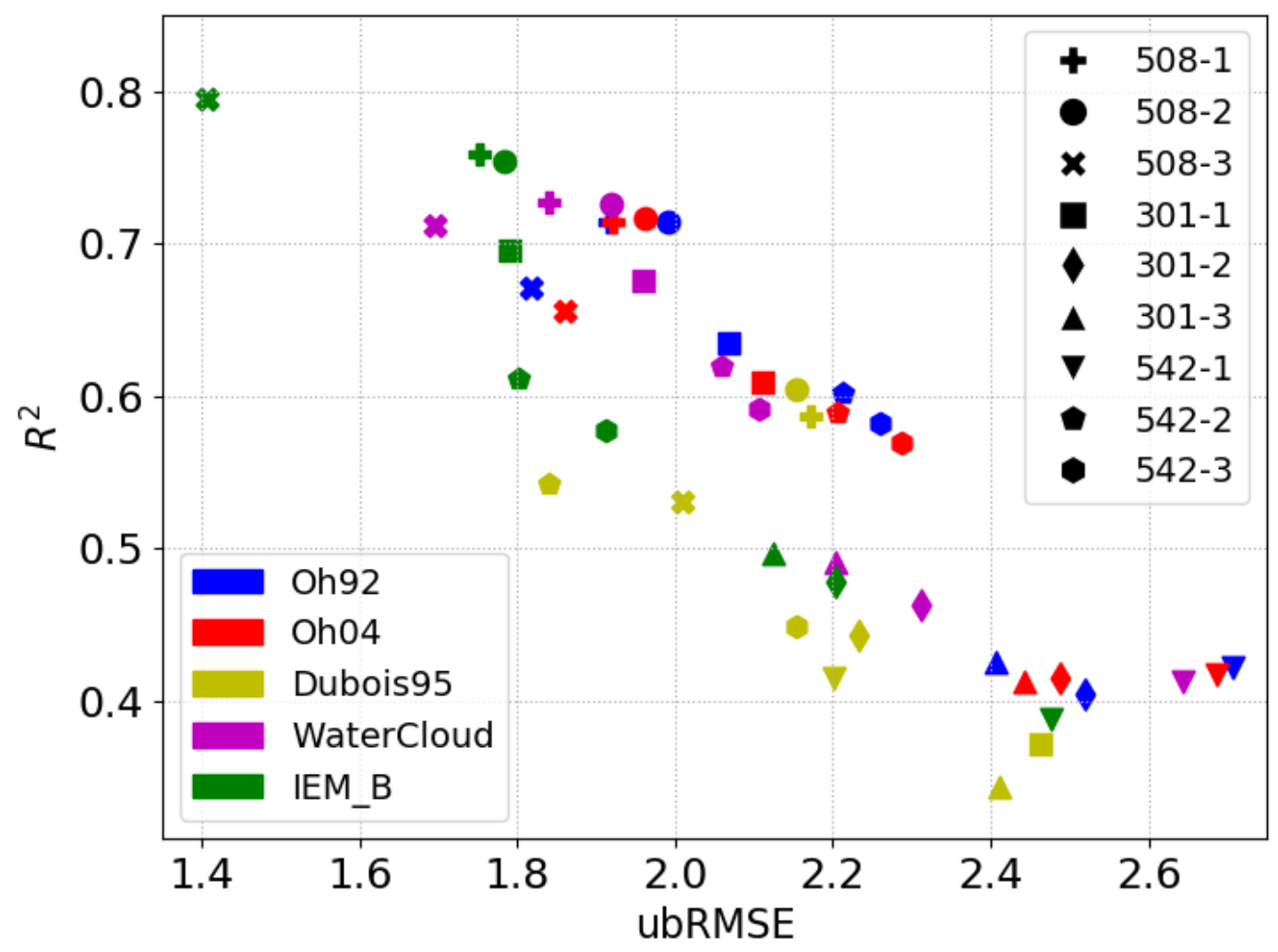

Figure 11. Scatter plot showing statistical validation results (correlation coefficient $R^{2}$ and ubRMSE) for canopy model WCM separated by different surface models (colors) and different field points (icons).

\subsection{Model Validation Results}

The validation for the non-static approach was performed by a leave-one-out cross-validation method. Means of RMSE, ubRMSE, and $\mathrm{R}^{2}$ are shown in Table 7. The results for the non-static approach show ubRMSE values between 1.92 and 2.22dB. All validation (ubRMSE) results are in a range of 0.65 to $0.95 \mathrm{~dB}$ poorer than the calibration (RMSE) results. Furthermore, for the validation results $\mathrm{R}^{2}$ ranges between 0.49 and 0.64 , whereas the poorest results are archived with surface model Dubois95. A comparison of ubRMSE for canopy model SSRT and WCM yields for all surface models slightly better results for canopy model SSRT. A more detailed overview of the validation results separated by models and measurement points is given in Figure 10 for canopy model SSRT and in Figure 11 for canopy model WCM. Comparing different fields, as well as field measurement points, a diverse picture is drawn. In general, field 508, especially 508-1, shows the best results, with $\mathrm{R}^{2}$ values mainly higher than 0.6 and ubRMSE lower than 2.2. Field 542, and especially 542-1, show the worst results, with $\mathrm{R}^{2}$ around 0.4 and ubRMSE higher than 2.2. Comparing different surface model combinations, IEM_B and WCM show, for both canopy models, slightly better results than the others. It is noticeable that the results of Dubois95 are, in general, poorer than the results of the other surface models, with the exception of point 542-1 (measurement point with the poorest overall results) and partly 301-2. Differences between $\mathrm{Oh} 92$ and $\mathrm{Oh} 04$ for the different measurement points are present but, compared to the other models, very low. A closer look into each model combination, and especially at the used non-static empirical parameters coef and $B$, and thus at the change of the attenuation of the canopy in time, are given with Figures 8 and 9. The figures show the development of coef and $B$ over the vegetation period and the parameter calibration spread, which is defined by the used leave-one-out cross-validation results. Comparing different surface models, the same evolution over time (except Dubois 95 for the first half of the vegetation period), with some differences in the absolute values, can be observed. The low values of coef and $B$ for model Dubois 95 in the first half of the vegetation period can explain the differences in absolute values of $T$ (Figure 7, bottom part) between Dubois95 
and the other model combinations. A comparison of canopy model SSRT (parameter coef) and WCM (parameter $B$ ) show, for all surface models (except Dubois95), for parameter coef, a almost steady decrease from the beginning to the end of the vegetation period and a similar evolution for parameter $B$, except for a short period of increasing values to a relative maximum from mid-May to the end of May. The differences in shape between coef and $B$ might be explained due to different model input data. SSRT uses the canopy height and LAI for the description of the canopy, whereas WCM only uses LAI. The increase of parameter $B$ correlates very well with the measured increase of the canopy height. This suggests that parameter $B$ compensates for possible shortcomings of WCM due to missing information about the canopy height. Furthermore, not only the absolute values but also the spread of coef and $B$ for different models are higher at the beginning of the vegetation period and strongly decrease over time. This means that coef and $B$ show higher differences between fields and field measurement points at the beginning of the vegetation period. This is in line with observations made during the field campaign, where higher differences within one field and between fields could be observed more easily at early vegetation stages. At the end of the vegetation period, such differences were not detectable anymore. Another indicator of low field differences regarding the ripening stage of the wheat plants was the almost simultaneous harvesting date. Another factor to be considered if looking at higher variability of coef and $B$ at the beginning of the vegetation season is the model implementation itself. $B$ and coe $f$ are influencing the attenuation of the backscatter by the canopy and therefore how strong each model compartment (surface or canopy) contributes to the total backscatter calculation. At the beginning of the growing season, LAI and canopy height are low; therefore, notable differences within coef and $B$ might have not such a high impact on total backscatter predictions. Differences in the range of coef ( 0 to 2.5 ) and $B$ (from 0 to 0.35 ) are most likely based on differences between the model definitions and the required input parameters.

\section{Conclusions}

Modeled backscatter results of wheat field time series data using different RT model combinations (surface: Oh92, Oh04, Dubois95, IEM_B, WCM; canopy: WCM, SSRT) were compared to observed C-band data from Sentinel-1. Differences between the models were analyzed. The used dataset was acquired by an intense field campaign throughout one vegetation period in 2017 . The analysis focused on coupled performance of surface and canopy models and especially on how changes of backscatter attenuation through the canopy influence the total backscatter calculation for different vegetation stages. The two novelties of this study are the evaluation of different combinations of widely used surface and canopy RT models on one test site and the analysis over time of empirical model parameters coef (SSRT) and B (WCM) describing the backscatter attenuation through the canopy $T$.

Results show that, for total LAI, as vegetation descriptor, a static parameter influencing the backscatter attenuation through the canopy is suitable for the first half but not for the second half of the vegetation period. By using a non-static parameter approach, the backscatter increase at the end of the vegetation period can be modeled. The static calibration performance results in the form of RMSE improved from 1.92-2.25dB to $1.13-1.60 \mathrm{~dB}$ for the non-static approach. The validation accuracy for the non-static parameter approach was evaluated with ubRMSE and ranges for all model combinations between 1.82 and 2.22dB. Validation results with SSRT as canopy model show better results in combination with all surface models when compared to respective combinations using WCM for the canopy part. Furthermore, it has been shown that the modeled backscatter results highly depend on the non-static empirical parameter. The evolution of the empirical parameter is similar for all surface models except Dubois95. At the beginning of the vegetation period, high values are observed, which decrease during the vegetation season to a minimum shortly before harvesting. Differences between the canopy model SSRT and WCM are noticeable in the form of higher variability (more outliers) of the empirical parameter from canopy model WCM. Furthermore, the empirical parameter for canopy model WCM has a relative maximum at the end of June. This increase of WCM's empirical parameter $B$ can most likely be explained by not including information about the canopy 
height. Overall, the results of this study indicate that more complex models, like IEM_B as surface and SSRT as canopy model, provide the best results in our setup regarding ubRMSE and $\mathrm{R}^{2}$. It should be mentioned that the disadvantage of more complex models, by requiring more input parameters, were set to a minimum because of model parameter reduction by model adjustments and the use of literature values for rms height and single scattering albedo. Therefore, based on this study, we suggest using surface model IEM_B in combination with canopy model SSRT.

To accomplish a very dense time series of satellite acquisitions with a revisit time of 1.5 days, Sentinel-1 images with different incidence and azimuth angles were used. The models can account for backscatter changes due to different acquisition geometries only during the first half of the vegetation period. During the second half, a trend mismatch between Sentinel-1 and modeled backscatter is apparent in all model results. Therefore, it has to be stated that the used models in this study are only partially able to handle differences due to changes in radar acquisition geometries.

To take full advantage of dense time series provided, e.g., by incorporating different sensors on top of varying radar acquisition geometries, extended research on the suitability of certain RT models is required. Respectively, arising radiometric differences added to the disparity in radar acquisition geometries must be investigated, for that matter. To advance synergistic retrieval methods of SAR and optical data for soil moisture estimation, further research on incorporating non-static empirical parameter sets retrieved from optical sensors, to account for vegetation phenological states, is needed.

Author Contributions: Conceptualization, T.W. and A.L.; Methodology and Formal Analysis, T.W.; Software, T.W. and A.L.; Writing-Original Draft Preparation, T.W., Writing-Review \& Editing, T.W., T.R. and P.M.; Resources, T.W. and T.R.; Visualization, T.W.; Supervision, A.L and P.M.; Project administration, A.L. and P.M.; Funding acquisition, A.L. All authors have read and agreed to the published version of the manuscript.

Funding: The project leading to this application has received funding from the European Union's Horizon 2020 research and innovation program under Grant Agreement No. 687320.

Acknowledgments: Thomas Weiß is truly thankful for the inspiration, ideas, and support that Alexander Löw († 2. July 2017) has given him.

Conflicts of Interest: The authors declare no conflict of interest.

\section{References}

1. Hollmann, R.; Merchant, C.J.; Saunders, R.; Downy, C.; Buchwitz, M.; Cazenave, A.; Chuvieco, E.; Defourny, P.; de Leeuw, G.; Forsberg, R.; et al. The ESA Climate Change Initiative: Satellite Data Records for Essential Climate Variables. Bull. Am. Meteorol. Soc. 2013, 94, 1541-1552. [CrossRef]

2. Brocca, L.; Ciabatta, L.; Massari, C.; Camici, S.; Tarpanelli, A. Soil Moisture for Hydrological Applications: Open Questions and New Opportunities. Water 2017, 9, 140. [CrossRef]

3. Hochschild, V.; Thiel, C.; Grünler, S. Derivation of Land Cover and Soil Moisture from Airborne Polarimetric SAR-Data. Sao/NASA Astrophys. Data Syst. 2001, 475, 355-358.

4. Zribi, M.; Muddu, S.; Bousbih, S.; Al Bitar, A.; Tomer, S.K.; Baghdadi, N.; Bandyopadhyay, S. Analysis of L-Band SAR Data for Soil Moisture Estimations over Agricultural Areas in the Tropics. Remote Sens. 2019, 11, 1122. [CrossRef]

5. Oldak, A.; Jackson, T.J.; Starks, P.; Elliott, R. Mapping Near-Surface Soil Moisture on Regional Scale Using ERS-2 SAR Data. Int. J. Remote Sens. 2003, 24, 4579-4598. [CrossRef]

6. Baghdadi, N.; Aubert, M.; Cerdan, O.; Franchistéguy, L.; Viel, C.; Martin, E.; Zribi, M.; Desprats, J.F. Operational Mapping of Soil Moisture Using Synthetic Aperture Radar Data: Application to the Touch Basin (France). Sensors 2007, 7, 2458-2483. [CrossRef]

7. Kornelsen, K.C.; Coulibaly, P. Advances in Soil Moisture Retrieval from Synthetic Aperture Radar and Hydrological Applications. J. Hydrol. 2013, 476, 460-489. [CrossRef]

8. Engman, E. The Potential of SAR in Hydrology. In Proceedings of the IGARSS '94-1994 IEEE International Geoscience and Remote Sensing Symposium, Pasadena, CA, USA, 8-12 August 1994; Volume 1, pp. 283-285. [CrossRef] 
9. Le Hegarat-Mascle, S.; Zribi, M.; Alem, F.; Weisse, A.; Loumagne, C. Soil Moisture Estimation from ERS/SAR Data: Toward an Operational Methodology. IEEE Trans. Geosci. Remote Sens. 2002, 40, 2647-2658. [CrossRef]

10. Dorigo, W.; Wagner, W.; Albergel, C.; Albrecht, F.; Balsamo, G.; Brocca, L.; Chung, D.; Ertl, M.; Forkel, M.; Gruber, A.; et al. ESA CCI Soil Moisture for Improved Earth System Understanding: State-of-the Art and Future Directions. Remote Sens. Environ. 2017, 203, 185-215. [CrossRef]

11. Amitrano, D.; Martino, G.D.; Iodice, A.; Riccio, D.; Ruello, G.; Ciervo, F.; Papa, M.N.; Koussoubé, Y. Effectiveness of High-Resolution SAR for Water Resource Management in Low-Income Semi-Arid Countries. Int. J. Remote Sens. 2014, 35, 70-88. [CrossRef]

12. Holtgrave, A.K.; Förster, M.; Greifeneder, F.; Notarnicola, C.; Kleinschmit, B. Estimation of Soil Moisture in Vegetation-Covered Floodplains with Sentinel-1 SAR Data Using Support Vector Regression. PFG J. Photogramm. Remote. Sens. Geoinf. Sci. 2018, 86, 85-101. [CrossRef]

13. Urban, M.; Berger, C.; Mudau, T.E.; Heckel, K.; Truckenbrodt, J.; Onyango Odipo, V.; Smit, I.P.J.; Schmullius, C. Surface Moisture and Vegetation Cover Analysis for Drought Monitoring in the Southern Kruger National Park Using Sentinel-1, Sentinel-2, and Landsat-8. Remote Sens. 2018, 10, 1482. [CrossRef]

14. Bousbih, S.; Zribi, M.; El Hajj, M.; Baghdadi, N.; Lili-Chabaane, Z.; Gao, Q.; Fanise, P. Soil Moisture and Irrigation Mapping in A Semi-Arid Region, Based on the Synergetic Use of Sentinel-1 and Sentinel-2 Data. Remote Sens. 2018, 10, 1953. [CrossRef]

15. Barrett, B.W.; Dwyer, E.; Whelan, P. Soil Moisture Retrieval from Active Spaceborne Microwave Observations: An Evaluation of Current Techniques. Remote Sens. 2009, 1, 210-242. [CrossRef]

16. Ulaby, F. Radar Measurement of Soil Moisture Content. IEEE Trans. Antennas Propag. 1974, 22, $257-265$. [CrossRef]

17. Ulaby, F.; Long, D.; Blackwell, W.; Elachi, C.; Fung, A.; Ruf, C.; Sarabandi, K.; Zyl, J.; Zebker, H. Microwave Radar and Radiometric Remote Sensing; University of Michigan Press: Ann Arbor, MI, USA, 2014.

18. Baghdadi, N.; King, C.; Bourguignon, A.; Remond, A. Potential of ERS and Radarsat Data for Surface Roughness Monitoring over Bare Agricultural Fields: Application to Catchments in Northern France. Int. J. Remote Sens. 2002, 23, 3427-3442. [CrossRef]

19. Holah, N.; Baghdadi, N.; Zribi, M.; Bruand, A.; King, C. Potential of ASAR/ENVISAT for the Characterization of Soil Surface Parameters over Bare Agricultural Fields. Remote Sens. Environ. 2005, 96, 78-86. [CrossRef]

20. Wickel, A.J.; Jackson, T.J.; Wood, E.F. Multitemporal Monitoring of Soil Moisture with RADARSAT SAR during the 1997 Southern Great Plains Hydrology Experiment. Int. J. Remote Sens. 2001, 22, 1571-1583. [CrossRef]

21. Mathieu, R.; Sbih, M.; Viau, A.A.; Anctil, F.; Parent, L.E.; Boisvert, J. Relationships between Radarsat SAR Data and Surface Moisture Content of Agricultural Organic Soils. Int. J. Remote Sens. 2003, 24, 5265-5281. [CrossRef]

22. Attema, E.P.W.; Ulaby, F.T. Vegetation Modeled as a Water Cloud. Radio Sci. 1978, 13, 357-364. [CrossRef]

23. Prévot, L.; Champion, I.; Guyot, G. Estimating Surface Soil Moisture and Leaf Area Index of a Wheat Canopy Using a Dual-Frequency (C and X Bands) Scatterometer. Remote Sens. Environ. 1993, 46, 331-339. [CrossRef]

24. Champion, I.; Prevot, L.; Guyot, G. Generalized Semi-Empirical Modelling of Wheat Radar Response. Int. J. Remote Sens. 2000, 21, 1945-1951. [CrossRef]

25. Dabrowska-Zielinska, K.; Inoue, Y.; Kowalik, W.; Gruszczynska, M. Inferring the Effect of Plant and Soil Variables on C- and L-Band SAR Backscatter over Agricultural Fields, Based on Model Analysis. Adv. Space Res. 2007, 39, 139-148. [CrossRef]

26. Oh, Y.; Sarabandi, K.; Ulaby, F. An Empirical Model and an Inversion Technique for Radar Scattering from Bare Soil Surfaces. IEEE Trans. Geosci. Remote Sens. 1992, 30, 370-381. [CrossRef]

27. Oh, Y. Quantitative Retrieval of Soil Moisture Content and Surface Roughness from Multipolarized Radar Observations of Bare Soil Surfaces. IEEE Trans. Geosci. Remote Sens. 2004, 42, 596-601. [CrossRef]

28. Dubois, P.; van Zyl, J.; Engman, T. Measuring Soil Moisture with Imaging Radars. IEEE Trans. Geosci. Remote Sens. 1995, 33, 915-926. [CrossRef]

29. Fung, A.; Li, Z.; Chen, K. Backscattering from a Randomly Rough Dielectric Surface. IEEE Trans. Geosci. Remote Sens. 1992, 30, 356-369. [CrossRef] 
30. Baghdadi, N.; King, C.; Chanzy, A.; Wigneron, J.P. An Empirical Calibration of the Integral Equation Model Based on SAR Data, Soil Moisture and Surface Roughness Measurement over Bare Soils. Int. J. Remote Sens. 2002, 23, 4325-4340. [CrossRef]

31. Baghdadi, N.; Abou Chaaya, J.; Zribi, M. Semiempirical Calibration of the Integral Equation Model for SAR Data in C-Band and Cross Polarization Using Radar Images and Field Measurements. IEEE Geosci. Remote Sens. Lett. 2011, 8, 14-18. [CrossRef]

32. Chen, K.; Wu, T.D.; Tsang, L.; Li, Q.; Shi, J.; Fung, A. Emission of Rough Surfaces Calculated by the Integral Equation Method with Comparison to Three-Dimensional Moment Method Simulations. IEEE Trans. Geosci. Remote Sens. 2003, 41, 90-101. [CrossRef]

33. Ulaby, F.T.; Sarabandi, K.; McDonald, K.; Whitt, M.; Dobson, M.C. Michigan Microwave Canopy Scattering Model. Int. J. Remote Sens. 1990, 11, 1223-1253. [CrossRef]

34. Ferrazzoli, P.; Guerriero, L. Radar Sensitivity to Tree Geometry and Woody Volume: A Model Analysis. IEEE Trans. Geosci. Remote Sens. 1995, 33, 360-371. [CrossRef]

35. De Roo, R.; Du, Y.; Ulaby, F.; Dobson, M. A Semi-Empirical Backscattering Model at L-Band and C-Band for a Soybean Canopy with Soil Moisture Inversion. IEEE Trans. Geosci. Remote Sens. 2001, 39, 864-872. [CrossRef]

36. Quast, R.; Wagner, W. Analytical Solution for First-Order Scattering in Bistatic Radiative Transfer Interaction Problems of Layered Media. Appl. Opt. 2016, 55, 5379-5386. [CrossRef] [PubMed]

37. Quast, R.; Albergel, C.; Calvet, J.C.; Wagner, W. A Generic First-Order Radiative Transfer Modelling Approach for the Inversion of Soil and Vegetation Parameters from Scatterometer Observations. Remote Sens. 2019, 11, 285. [CrossRef]

38. Zribi, M.; Taconet, O.; Le Hégarat-Mascle, S.; Vidal-Madjar, D.; Emblanch, C.; Loumagne, C.; Normand, M. Backscattering Behavior and Simulation Comparison over Bare Soils Using SIR-C/X-SAR and ERASME 1994 Data over Orgeval. Remote Sens. Environ. 1997, 59, 256-266. [CrossRef]

39. Baghdadi, N.; Zribi, M. Evaluation of Radar Backscatter Models IEM, OH and Dubois Using Experimental Observations. Int. J. Remote Sens. 2006, 27, 3831-3852. [CrossRef]

40. Khabazan, S.; Motagh, M.; Hosseini, M. Evaluation of Radar Backscattering Models IEM, OH, and Dubois Using L and C-Bands SAR Data over Different Vegetation Canopy Covers and Soil Depths. In ISPRS-International Archives of the Photogrammetry, Remote Sensing and Spatial Information Sciences; Copernicus GmbH: Göttingen, Germany, 2013; Volume XL-1-W3, pp. 225-230. [CrossRef]

41. Choker, M.; Baghdadi, N.; Zribi, M.; El Hajj, M.; Paloscia, S.; Verhoest, N.E.C.; Lievens, H.; Mattia, F. Evaluation of the Oh, Dubois and IEM Backscatter Models Using a Large Dataset of SAR Data and Experimental Soil Measurements. Water 2017, 9, 38. [CrossRef]

42. Ezzahar, J.; Ouaadi, N.; Zribi, M.; Elfarkh, J.; Aouade, G.; Khabba, S.; Er-Raki, S.; Chehbouni, A.; Jarlan, L. Evaluation of Backscattering Models and Support Vector Machine for the Retrieval of Bare Soil Moisture from Sentinel-1 Data. Remote Sens. 2020, 12, 72. [CrossRef]

43. Kweon, S.K.; Oh, Y. A Modified Water-Cloud Model With Leaf Angle Parameters for Microwave Backscattering From Agricultural Fields. IEEE Trans. Geosci. Remote Sens. 2015, 53, 2802-2809. [CrossRef]

44. Pierdicca, N.; Pulvirenti, L.; Pace, G. A Prototype Software Package to Retrieve Soil Moisture From Sentinel-1 Data by Using a Bayesian Multitemporal Algorithm. IEEE J. Sel. Top. Appl. Earth Obs. Remote Sens. 2014, 7, 153-166. [CrossRef]

45. Baghdadi, N.; El Hajj, M.; Zribi, M.; Bousbih, S. Calibration of the Water Cloud Model at C-Band for Winter Crop Fields and Grasslands. Remote Sens. 2017, 9, 969. [CrossRef]

46. Graham, A.J.; Harris, R. Estimating Crop and Waveband Specific Water Cloud Model Parameters Using a Theoretical Backscatter Model. Int. J. Remote Sens. 2002, 23, 5129-5133. [CrossRef]

47. Liu, C.; Shi, J. Estimation of Vegetation Parameters of Water Cloud Model for Global Soil Moisture Retrieval Using Time-Series L-Band Aquarius Observations. IEEE J. Sel. Top. Appl. Earth Obs. Remote Sens. 2016, 9, 5621-5633. [CrossRef]

48. Kumar, K.; Prasad, K.S.H.; Arora, M.K. Estimation of Water Cloud Model Vegetation Parameters Using a Genetic Algorithm. Hydrol. Sci. J. 2012, 57, 776-789. [CrossRef]

49. Kumar, K.; Rao, H.P.S.; Arora, M.K. Study of Water Cloud Model Vegetation Descriptors in Estimating Soil Moisture in Solani Catchment. Hydrol. Process. 2015, 29, 2137-2148. [CrossRef] 
50. Song, X.; Ma, J.; Li, X.; Leng, P.; Zhou, F.; Li, S. First Results of Estimating Surface Soil Moisture in the Vegetated Areas Using ASAR and Hyperion Data: The Chinese Heihe River Basin Case Study. Remote Sens. 2014, 6, 12055-12069. [CrossRef]

51. van Emmerik, T.; Steele-Dunne, S.C.; Judge, J.; van de Giesen, N. Impact of Diurnal Variation in Vegetation Water Content on Radar Backscatter From Maize During Water Stress. IEEE Trans. Geosci. Remote Sens. 2015, 53, 3855-3869. [CrossRef]

52. Xu, C.; Qu, J.J.; Hao, X.; Wu, D. Monitoring Surface Soil Moisture Content over the Vegetated Area by Integrating Optical and SAR Satellite Observations in the Permafrost Region of Tibetan Plateau. Remote Sens. 2020, 12, 183. [CrossRef]

53. Lievens, H.; Verhoest, N.E.C. On the Retrieval of Soil Moisture in Wheat Fields From L-Band SAR Based on Water Cloud Modeling, the IEM, and Effective Roughness Parameters. IEEE Geosci. Remote Sens. Lett. 2011, 8, 740-744. [CrossRef]

54. Bai, X.; He, B. Potential of Dubois Model for Soil Moisture Retrieval in Prairie Areas Using SAR and Optical Data. Int. J. Remote Sens. 2015, 36, 5737-5753. [CrossRef]

55. Xing, M.; He, B.; Ni, X.; Wang, J.; An, G.; Shang, J.; Huang, X. Retrieving Surface Soil Moisture over Wheat and Soybean Fields during Growing Season Using Modified Water Cloud Model from Radarsat-2 SAR Data. Remote Sens. 2019, 11, 1956. [CrossRef]

56. He, B.; Xing, M.; Bai, X. A Synergistic Methodology for Soil Moisture Estimation in an Alpine Prairie Using Radar and Optical Satellite Data. Remote Sens. 2014, 6, 10966-10985. [CrossRef]

57. Qiu, J.; Crow, W.T.; Wagner, W.; Zhao, T. Effect of Vegetation Index Choice on Soil Moisture Retrievals via the Synergistic Use of Synthetic Aperture Radar and Optical Remote Sensing. Int. J. Appl. Earth Obs. Geoinf. 2019, 80, 47-57. [CrossRef]

58. Tao, L.; Wang, G.; Chen, W.; Chen, X.; Li, J.; Cai, Q. Soil Moisture Retrieval From SAR and Optical Data Using a Combined Model. IEEE J. Sel. Top. Appl. Earth Obs. Remote Sens. 2019, 12, 637-647. [CrossRef]

59. Zhao, X.; Huang, N.; Niu, Z.; Raghavan, V.; Song, X. Soil Moisture Retrieval in Farmland Using C-Band SAR and Optical Data. Spat. Inf. Res. 2017, 25, 431-438. [CrossRef]

60. Attarzadeh, R.; Amini, J.; Notarnicola, C.; Greifeneder, F. Synergetic Use of Sentinel-1 and Sentinel-2 Data for Soil Moisture Mapping at Plot Scale. Remote Sens. 2018, 10, 1285. [CrossRef]

61. El Hajj, M.; Baghdadi, N.; Zribi, M.; Bazzi, H. Synergic Use of Sentinel-1 and Sentinel-2 Images for Operational Soil Moisture Mapping at High Spatial Resolution over Agricultural Areas. Remote Sens. 2017, 9, 1292. [CrossRef]

62. Gao, F.; Morisette, J.T.; Wolfe, R.E.; Ederer, G.; Pedelty, J.; Masuoka, E.; Myneni, R.; Tan, B.; Nightingale, J. An Algorithm to Produce Temporally and Spatially Continuous MODIS-LAI Time Series. IEEE Geosci. Remote Sens. Lett. 2008, 5, 60-64. [CrossRef]

63. Dhakar, R.; Sehgal, V.K.; Chakraborty, D.; Sahoo, R.N.; Mukherjee, J. Field Scale Wheat LAI Retrieval from Multispectral Sentinel 2A-MSI and LandSat 8-OLI Imagery: Effect of Atmospheric Correction, Image Resolutions and Inversion Techniques. Geocarto Int. 2019, 1-21. [CrossRef]

64. Xie, Q.; Dash, J.; Huete, A.; Jiang, A.; Yin, G.; Ding, Y.; Peng, D.; Hall, C.C.; Brown, L.; Shi, Y.; et al. Retrieval of Crop Biophysical Parameters from Sentinel-2 Remote Sensing Imagery. Int. J. Appl. Earth Obs. Geoinf. 2019, 80, 187-195. [CrossRef]

65. Berger, K.; Atzberger, C.; Danner, M.; Wocher, M.; Mauser, W.; Hank, T. Modellbasierte Selektion Hyperspektraler EnMAP Kanäle Zur Optimalen Invertierung von Strahlungstransfermodellen Für Landwirtschaftliche Kulturen. PFG J. Photogramm. Remote Sens. Geoinf. Sci. 2018, 86, 263-272. [CrossRef]

66. Danner, M.; Berger, K.; Wocher, M.; Mauser, W.; Hank, T. Retrieval of Biophysical Crop Variables from Multi-Angular Canopy Spectroscopy. Remote Sens. 2017, 9, 726. [CrossRef]

67. Danner, M.; Berger, K.; Wocher, M.; Mauser, W.; Hank, T. Fitted PROSAIL Parameterization of Leaf Inclinations, Water Content and Brown Pigment Content for Winter Wheat and Maize Canopies. Remote Sens. 2019, 11, 1150. [CrossRef]

68. Wocher, M.; Berger, K.; Danner, M.; Mauser, W.; Hank, T. Physically-Based Retrieval of Canopy Equivalent Water Thickness Using Hyperspectral Data. Remote Sens. 2018, 10, 1924. [CrossRef]

69. Kellndorfer, J.; Pierce, L.; Dobson, M.; Ulaby, F. Toward Consistent Regional-to-Global-Scale Vegetation Characterization Using Orbital SAR Systems. IEEE Trans. Geosci. Remote Sens. 1998, 36, 1396-1411. [CrossRef] 
70. El Hajj, M.; Baghdadi, N.; Zribi, M.; Belaud, G.; Cheviron, B.; Courault, D.; Charron, F. Soil Moisture Retrieval over Irrigated Grassland Using X-Band SAR Data. Remote Sens. Environ. 2016, 176, 202-218. [CrossRef]

71. Fung, A.; Liu, W.; Chen, K.; Tsay, M. An Improved Iem Model for Bistatic Scattering From Rough Surfaces. J. Electromagn. Waves Appl. 2002, 16, 689-702. [CrossRef]

72. Marzahn, P.; Ludwig, R. Using Multi-Dimensional Microwave Remote Sensing Information for the Retrieval of Soil Surface Roughness. Int. Arch. Photogramm. Remote Sens. Spat. Inf. Sci. 2016, 41, 1257-1262 [CrossRef]

73. Marzahn, P.; Rieke-Zapp, D.; Ludwig, R. Assessment of Soil Surface Roughness Statistics for Microwave Remote Sensing Applications Using a Simple Photogrammetric Acquisition System. ISPRS J. Photogramm. Remote Sens. 2012, 72, 80-89. [CrossRef]

74. Wegmüller, U.; Santoro, M.; Mattia, F.; Balenzano, A.; Satalino, G.; Marzahn, P.; Fischer, G.; Ludwig, R.; Floury, N. Progress in the Understanding of Narrow Directional Microwave Scattering of Agricultural Fields. Remote Sens. Environ. 2011, 115, 2423-2433. [CrossRef]

75. Jia, M.; Tong, L.; Zhang, Y.; Chen, Y. Multitemporal Radar Backscattering Measurement of Wheat Fields Using Multifrequency (L, S, C, and X) and Full-Polarization. Radio Sci. 2013, 48, 471-481. [CrossRef]

76. Mattia, F.; Le Toan, T.; Picard, G.; Posa, F.; D’Alessio, A.; Notarnicola, C.; Gatti, A.; Rinaldi, M.; Satalino, G.; Pasquariello, G. Multitemporal C-Band Radar Measurements on Wheat Fields. IEEE Trans. Geosci. Remote Sens. 2003, 41, 1551-1560. [CrossRef]

77. Wigneron, J.P.; Kerr, Y.; Waldteufel, P.; Saleh, K.; Escorihuela, M.J.; Richaume, P.; Ferrazzoli, P.; de Rosnay, P.; Gurney, R.; Calvet, J.C.; et al. L-Band Microwave Emission of the Biosphere (L-MEB) Model: Description and Calibration against Experimental Data Sets over Crop Fields. Remote Sens. Environ. 2007, 107, 639-655. [CrossRef]

78. Davidson, M.; Toan, T.L.; Mattia, F.; Satalino, G.; Manninen, T.; Borgeaud, M. On the Characterization of Agricultural Soil Roughness for Radar Remote Sensing Studies. IEEE Trans. Geosci. Remote Sens. 2000, 38, 630-640. [CrossRef]

79. Picard, G.; Le Toan, T.; Mattia, F. Understanding C-Band Radar Backscatter from Wheat Canopy Using a Multiple-Scattering Coherent Model. IEEE Trans. Geosci. Remote Sens. 2003, 41, 1583-1591. [CrossRef]

80. Dobson, M.C.; Ulaby, F.T.; Hallikainen, M.T.; El-rayes, M.A. Microwave Dielectric Behavior of Wet Soil-Part II: Dielectric Mixing Models. IEEE Trans. Geosci. Remote Sens. 1985, GE-23, 35-46. [CrossRef]

81. Khabbazan, S.; Vermunt, P.; Steele-Dunne, S.; Ratering Arntz, L.; Marinetti, C.; van der Valk, D.; Iannini, L.; Molijn, R.; Westerdijk, K.; van der Sande, C. Crop Monitoring Using Sentinel-1 Data: A Case Study from The Netherlands. Remote Sens. 2019, 11, 1887. [CrossRef]

82. Allen, S.T.; Whitsell, M.L.; Keim, R.F. Leaf Area Allometrics and Morphometrics in Baldcypress. Can. J. For. Res. 2015, 45, 963-969. [CrossRef]

83. He, L.; Tong, L.; Li, Y.; Chen, Y.; Tan, L.; Guo, C. Polarimetric Analysis of Radar Backscatter from Ground-Based Scatterometers and Wheat Biomass Monitoring with Advanced Synthetic Aperture Radar Images. J. Appl. Remote Sens. 2016, 10, 026008. [CrossRef]

84. Meier, U.; Bleiholder, H.; Buhr, L.; Feller, C.; Hack, H.; Heß, M.; Lancashire, P.D.; Schnock, U.; Stauß, R.; van den Boom, T.; et al. The BBCH System to Coding the Phenological Growth Stages of Plants-History and Publications. J. FÜr Kult. 2009, 61, 41-52. [CrossRef]

85. Riedel, T.; Liebeskind, P.; Schmullius, C. Seasonal and Diurnal Changes of Polarimetric Parameters from Crops Derived by the Cloude Decomposition Theorem at L-Band. In Proceedings of the IEEE International Geoscience and Remote Sensing Symposium, Toronto, ON, Canada, 24-28 June 2002; Volume 5, pp. 2714-2716. [CrossRef]

86. Riedel, T.; Pathe, C.; Thiel, C.; Herold, M.; Schmullius, C. Systematic Investigation on the Effect of Dew and Interception on Multifrequency and Multipolarimetric Radar Backscatter Signals. Sao/NASA Astrophys. Data Syst. 2002, 475, 99-104.

87. Way, J.; Paris, J.; Dobson, M.; McDonals, K.; Ulaby, F.; Weber, J.; Ustin, L.; Vanderbilt, V.; Kasischke, E. Diurnal Change in Trees as Observed by Optical and Microwave Sensors: The EOS Synergism Study. IEEE Trans. Geosci. Remote Sens. 1991, 29, 807. [CrossRef] 
88. Hornbuckle, B.K.; Rowlandson, T.L.; Russell, E.; Kaleita, A.; Logsdon, S.; Kruger, A.; Yueh, S.; De Roo, R.D. Howdoes Dew Affect L-Band Backscatter? Analysis of Pals Data at the Iowa Validation Site and Implications for Smap. In Proceedings of the 2010 IEEE International Geoscience and Remote Sensing Symposium, Honolulu, HI, USA, 25-30 July 2010; pp. 4835-4838. [CrossRef]

89. Konings, A.G.; Piles, M.; Rötzer, K.; McColl, K.A.; Chan, S.K.; Entekhabi, D. Vegetation Optical Depth and Scattering Albedo Retrieval Using Time Series of Dual-Polarized L-Band Radiometer Observations. Remote Sens. Environ. 2016, 172, 178-189. [CrossRef]

(C) 2020 by the authors. Licensee MDPI, Basel, Switzerland. This article is an open access article distributed under the terms and conditions of the Creative Commons Attribution (CC BY) license (http://creativecommons.org/licenses/by/4.0/). 